\title{
Determination of Distribution Equilibrium-Potential Differences Based on Extraction with Several Crown Ethers by Nitrobenzene, 1,2-Dichloroethane and Dichloromethane
}

\author{
Yoshihiro Kudo ${ }^{1}$, Tomohiro Amano ${ }^{2}$, Satoshi Ikeda ${ }^{1}$ \\ ${ }^{1}$ Graduate School of Science, Chiba University, Chiba 263-8522, Japan \\ ${ }^{2}$ Department of Chemistry, Faculty of Science, Chiba University, Chiba 263-8522, Japan \\ Correspondence: Yoshihiro Kudo, Graduate School of Science, Chiba University, Chiba 263-8522, Japan. \\ Tel: 81-43-290-2786. E-mail: iakudo@faculty.chiba-u.jp
}

Received: October 6, 2017 Accepted: November 2, $2017 \quad$ Online Published: November 2, 2017

doi:10.5539/ijc.v9n4p110

URL: https://doi.org/10.5539/ijc.v9n4p110

\begin{abstract}
Extraction constants $\left(K_{\mathrm{ex} \pm} \& K_{\mathrm{ex}}\right)$ were determined at $298 \mathrm{~K}$ for the extraction of sodium picrate (NaPic) by nitrobenzene (NB), 1,2-dichloroethane (DCE) and dichloromethane using 3m-crown- $m$ ethers and their benzo-derivatives $(m=5,6$; abbreviated as L) together with the determination of conditional distribution constants $\left(K_{\mathrm{D}, \mathrm{Pic}}\right)$ of picrate ion, $\mathrm{Pic}^{-}$, into these diluents. The $K_{1, \mathrm{org}}\left(=[\mathrm{NaLPic}]_{\text {org }} /\left[\mathrm{NaL}^{+}\right]_{\text {org }}\left[\mathrm{Pic}^{-}\right]_{\text {org }}\right)$ values at the organic (org)

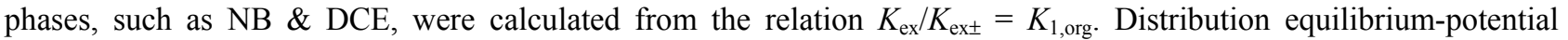
differences $\left(\Delta \phi_{\mathrm{eq}}\right)$ at extraction equilibria were evaluated from the equation $\Delta \phi_{\mathrm{eq}}=-0.05916 \times\left(\log K_{\mathrm{D}, \text { Pic }}-\right.$ constant $)$ at $298 \mathrm{~K}$. Correlations of the above equilibrium constants, particularly $K_{\text {ex } \pm}$, with $\Delta \phi_{\text {eq }}$ were examined. Furthermore, the standard formal potentials for $\mathrm{Na}^{+}$transfers across the interfaces were briefly evaluated from calculated $\Delta \phi_{\mathrm{eq}},\left[\mathrm{Na}^{+}\right]$and $\left[\mathrm{Pic}^{-}\right]_{\text {org }}$. The above extraction systems were characterized by $K_{1, \text { org }}$ and the complex formation constants of $\mathrm{Na}^{+}$with $\mathrm{L}$ in the org phases.
\end{abstract}

Keywords: distribution equilibrium potentials, conditional distribution constant of an ion, extraction constants, sodium picrate, crown ethers, nitrobenzene, 1,2-dichloroethane, dichloromethane

\section{Introduction}

In our previous papers (Kudo \& Takeuchi, 2014; Kudo \& Katsuta, 2015), distribution equilibrium-potential difference (dep, $\Delta \phi_{\text {eq }}$ as a symbol) has been reported through studies of extraction of some metal picrates $\left\{\right.$ AgPic $\&$ MPic $_{2}$ with M $=\mathrm{Ca}(\mathrm{II}), \mathrm{Sr}(\mathrm{II}) \& \mathrm{Ba}(\mathrm{II})\}$ by several diluents, such as 1,2-dichloroethane (DCE) and nitrobenzene (NB), using crown ethers (L), such as 18-crown-6 ether (18C6) and benzo-18C6 (B18C6). In these studies, the dep values have been experimentally determined using the equation $\log K_{\mathrm{D}, \mathrm{A}}=-\left\{\Delta \phi_{\mathrm{eq}}-(\right.$ standard formal potential $\left.)\right\} / 0.05916$ at $298 \mathrm{~K}$, where $K_{\mathrm{D}, \mathrm{A}}$ is a conditional distribution constant of $\mathrm{A}^{-}$into an organic (org) phase under the condition of $\Delta \phi_{\mathrm{eq}} \neq 0 \mathrm{~V}$ (Kudo \& Takeuchi, 2014; Kudo et al., 2014; Kudo et al., 2015). Additionally, it has been proved that such $\Delta \phi_{\mathrm{eq}}$ values are essentially equal to equilibrium potentials that are calculated electrochemically from charge balance equations of ionic species in the org phases (Kudo \& Katsuta, 2015; Takeda et al., 1995a). These facts have shown that the $\Delta \phi_{\text {eq }}$ values are related to the equilibrium interfacial potentials determined by electrochemical measurements at liquid/liquid interfaces (Markin \& Volkov, 1989).

Of course, even if the dep is included in the extraction processes, extraction constants, $K_{\mathrm{ex} \pm}$ and $K_{\mathrm{ex}}$, have to satisfy the equilibrium condition that is the free energy change $\left(\Delta G_{\mathrm{ex} \pm} \& \Delta G_{\mathrm{ex}}\right)$ of zero in the total extraction system. That is, the two constants could be thermodynamically expressed under the condition without $\Delta \phi_{\mathrm{eq}}$ (Kudo, 2015). The constants, $K_{\text {ex } \pm}$ and $K_{\text {ex }}$, have been defined as $\left[\mathrm{ML}^{z+}\right]_{\text {org }}\left[\mathrm{A}^{-}\right]_{\text {org }}^{z} / P$ and $\left[\mathrm{MLA}_{z}\right]_{\mathrm{org}} / P$, respectively, where $P=\left[\mathrm{M}^{z+}\right][\mathrm{L}]_{\mathrm{org}}\left[\mathrm{A}^{-}\right]^{z}$ and $z(=$ $1,2, \ldots$ ) is a formal charge of the simple metal or complex ion (Kudo \& Takeuchi, 2014; Kudo \& Katsuta, 2015; Kudo et al., 2016; Kudo et al., 2014a; Kudo et al., 2015; Makrlík \& Vaňura, 1999; Kikuchi \& Sakamoto, 2000; Kudo et al., 2016a; Levitskaia et al., 2007).

However, in comparison with the studies (Kudo \& Takeuchi, 2014) for the M(II) extraction with L, systematic studies for the M(I) extraction with some L into NB and DCE are still few. In particular, these two diluents have been often employed for experiments in the both fields of extraction chemistry and electrochemistry at the liquid/liquid interfaces (Markin \& Volkov, 1989; Osakai \& Ebina, 1998). Besides, the study for various L with 15-membered and 18-membered 
rings will make the presence of dep in the extraction systems surer.

In the present work, we tried to expand such examples to the NaPic extraction systems with 15 -crown-5 ether (15C5), 18C6, benzo-15C5 (B15C5) and B18C6. NB, DCE and dichloromethane (DCM) were selected in this study as diluents for the experiments, because of their polarities (Lide, 1995). The $\Delta \phi_{\mathrm{eq}}$ values were determined at $298 \mathrm{~K}$, using the two procedures that their values were obtained from the $K_{\text {D,Pic }}$ values (Kudo \& Takeuchi, 2014; Kudo \& Katsuta, 2015; Kudo et al., 2016; Kudo et al., 2014; Kudo et al., 2015) and the charge balance equations (Kudo \& Katsuta, 2015) which were proposed for ionic species present in the org phases. From these results, a dependence of $\log K_{\text {ex }}$ or $\log K_{\text {ex }}$ on $-\Delta \phi_{\text {eq }}$ was examined. Basically, the former values were proportional to the dep. Also, we discuss on the approximate method for determining standard formal potentials $\left(\Delta \phi_{\mathrm{Na}}{ }^{\prime \prime}\right)$ for $\mathrm{Na}^{+}$transfers across the water/DCE, water/NB and water/DCM interfaces. Further, these systems were characterized based on the ion-pair and complex formation in the org phases. On the NaPic extraction with some L and the less-polar diluent, benzene (Kudo et al, 2016a), a similar study has been already reported.

\section{Method}

\subsection{Chemicals}

Commercial NaPic monohydrate ( $>95.0 \%$, extra pure, Kanto) was used for the present extraction experiments (Kudo et al., 2011). Its purity was determined by an AAS measurement for $\mathrm{Na}(\mathrm{I})$, a spectrophotometric one for Pic(-I) and a Karl-Fischer titration for a water content. From these measurements, the ratio of $\mathrm{Na}(\mathrm{I}): \mathrm{Pic}(-\mathrm{I})$ was determined to be 1:1.06 and the content of water in the commercial NaPic, $\mathrm{NaPic} \cdot n \mathrm{H}_{2} \mathrm{O}$, to be $6.232 \pm 0.003 \%$ which corresponds to $n=$ 0.9263. Also, the water contents of commercial 15C5 (98\%, Acros), B15C5 ( $>96.0 \%$, Tokyo Chemical Industries) and $18 \mathrm{C} 6\left(98 \%\right.$, Aldrich) were determined by the titration to be $0.155 \pm 0.000_{1} \%, 0.003 \pm 0.000_{0}$ and $0.062 \pm 0.000_{3}$, respectively. The concentrations of these ethers were calculated as $100 \%$ purities from their weighed amounts. Nitrobenzene (guaranteed pure reagent, Kanto) was washed three times with water before use (Kudo \& Takeuchi, 2014; Kudo \& Katsuta, 2015; Kudo et al., 2015). Tap water was distilled once and then purified through Autopure system (type WT101-UV, Yamato/Millipore) (Kudo et al., 2014a). Such water was used for preparing all aqueous solutions and washing NB employed in this study.

\subsection{Extraction Experiments}

Aqueous solutions of NaPic $\left\{(3.4-7.0) \times 10^{-4} \mathrm{~mol} \mathrm{dm}^{-3}\right\}$ and those of $\mathrm{L}$ were mixed with NB saturated with water at equal volumes $\left(10\right.$ or $\left.12 \mathrm{~cm}^{3}\right)$ in stoppered glass tubes of about $30 \mathrm{~cm}^{3}$. Total concentrations of the $\mathrm{L}$ solutions were $(0.35-5.1) \times 10^{-4} \mathrm{~mol} \mathrm{dm}^{-3}$ for $\mathrm{L}=15 \mathrm{C} 5,0.0029-0.031$ for B15C5, $(0.10-6.2) \times 10^{-4}$ for $18 \mathrm{C} 6$ and $(0.10-6.4) \times 10^{-4}$ for B18C6. The glass tubes were shaken vigorously by hand and then agitated at $298 \mathrm{~K}\left(25 \pm 0.4{ }^{\circ} \mathrm{C}\right)$ for $2 \mathrm{~h}$ in a mechanical shaker (Kudo et al., 2016). After these operations, the two phases in the tubes were centrifuged and then the NB phases were separated by pipettes. The determination of total amounts of $\mathrm{Na}(\mathrm{I})$ extracted into the NB phase was done by the following two procedures.

Procedure (A). This procedure (Kudo \& Takeuchi, 2014; Kudo \& Katsuta, 2015; Kudo et al., 2015; Kudo et al., 2011) was employed for the 15C5, 18C6 and B18C6 systems. Amounts of water were added into the separated NB phases, then these mixtures were shaken by hand, and thereby the extracted species were back-extracted into these water phases. Such back-extraction experiments were repeated three times. The concentrations of all the $\mathrm{Na}(\mathrm{I})$ species back-extracted were determined at $589.0 \mathrm{~nm}$ by AAS measurements, for which a Hitachi atomic absorption spectrophotometer (type Z-6100) was used with an air-acetylene flame (Kudo et al., 2014; Kudo et al., 2015).

Procedure (B). The $\mathrm{Na}(\mathrm{I})$ concentrations of the separated water phases were directly determined by the AAS measurements, although the experimental accuracy might be lowered, compared with Procedure (A). This procedure was employed for only the $\mathrm{B} 15 \mathrm{C} 5$ system. There is reason why the back-extraction experiments with $\mathrm{B} 15 \mathrm{C} 5$ did not finish with three times.

In these experiments, blank ones without $\mathrm{L}$ were performed. A content of the blanks can correspond to $[\mathrm{NaPic}]_{\mathrm{NB}}+$ $\left[\mathrm{Na}^{+}\right]_{\mathrm{NB}}$. The $\mathrm{pH}$ values were measured at $298 \mathrm{~K}$ for the firstly-separated water phases using a Horiba $\mathrm{pH} /$ ion meter (type F-23) equipped with a pH electrode (Laqua, model 9615-10D) (Kudo et al., 2014).

\subsection{Data Analysis}

The extraction data of the DCM and DCE systems were the same as those (Takeda \& Takagi, 1994; Takeda et al., 1995; Takeda et al., 1998; Takeda et al., 2002) reported before by one (Y. K.) of us and his co-workers. The analytic procedure employed was essentially similar to that reported previously (Kudo et al., 2016; Kudo et al., 2014; Kudo et al., 2016a; Kudo et al., 2011a). The concentrations at equilibrium, $\left[\mathrm{Na}^{+}\right],[\mathrm{L}]_{\mathrm{NB}}$ and $\left[\mathrm{Pic}^{-}\right]$(see Appendix A), were calculated from experimental extraction data by a successive approximation method (Kudo et al., 2016; Kudo et al., 2014; Kudo et al., 2016a). The parameter, $K_{\mathrm{ex}}{ }^{\text {mix }}$ (Kudo et al., 2016; Kudo et al., 2014), was defined as ([NaLPic $\left.]_{\mathrm{NB}}+\left[\mathrm{NaL}^{+}\right]_{\mathrm{NB}}\right) / P$. Here, 
the $P$ value was estimated from the three concentrations at equilibrium and the numerator, $[\mathrm{NaLPic}]_{\mathrm{NB}}+\left[\mathrm{NaL}^{+}\right]_{\mathrm{NB}}$, of $K_{\text {ex }}{ }^{\text {mix }}$ has been calculated from $\{$ the total $\mathrm{Na}(\mathrm{I})$ concentration in the NB phase determined by AAS measurements $\}-$ \{blank value without $\mathrm{L}$ \}.

\section{Results and Discussion}

3.1 Determination of a Composition of Extracted Complexes and of Their $K_{\text {ext }} K_{D, A}, K_{e x}$ and $K_{l, o r g}$ Values

Plots of $\log \left(D_{\mathrm{Na}} /\left[\mathrm{Pic}^{-}\right]\right)$versus $\log [\mathrm{L}]_{\text {org }}$ for the determination of composition of species extracted into the org phase yield straight lines with slopes $(a)$ and intercepts $(b)$ in general (Kudo \& Katsuta, 2015; Kudo et al., 2014; Kudo et al., 2016a; Kudo et al., 2011a): see Appendix B. In this case, the $b$ values correspond to the $\log K_{\text {ex }}$ ones (Kudo et al., 2011a). Experimental lines obtained from these plots were

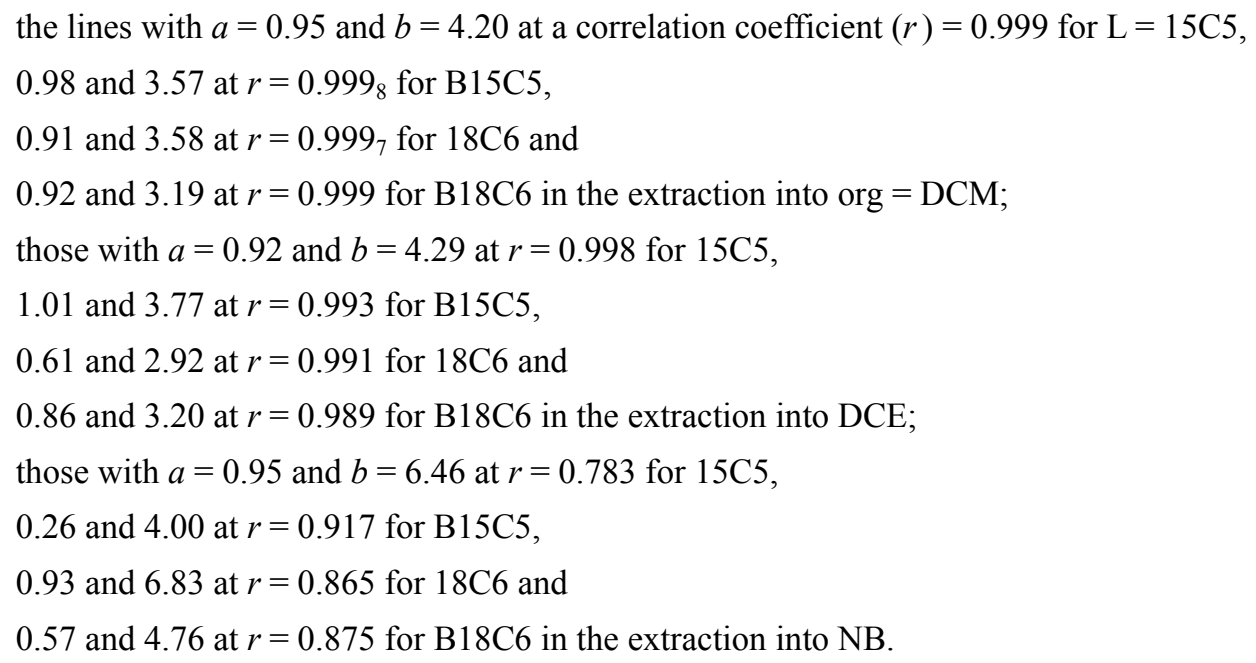

The $a$ values being in the range of less than 0.90 indicate that the extracted ion-pair complexes are dissociable in the org phases (Kudo et al., 2011a) (see the smaller $\log K_{1, \text { org }}$ values in Table 1 for their four systems). Similarly, the $a$ values less than 0.90 for the plots have been obtained in the $\mathrm{NaMnO}_{4}$ extraction with B18C6 into DCE, B15C5 or B18C6 into NB (Kudo et al., 2011a). Figure 1 shows examples of the plots for the four NB systems. Compositions of $\mathrm{Na}(\mathrm{I}): \mathrm{L}$ which equals 1:1 for extracted species were proved to the cases that the slopes of the plots were in the range of 0.90 to 1.10 (Kudo \& Takeuchi, 2014; Kudo \& Katsuta, 2015; Kudo et al., 2016; Kudo et al., 2014; Kudo et al., 2015; Kudo et al., 2016a; Kudo et al., 2011a). On the other hand, the ratios of $\mathrm{Na}(\mathrm{I}): \operatorname{Pic}(-\mathrm{I})$ were assumed to be 1:1 from the electroneutrality between $\mathrm{NaL}(\mathrm{I})$ and Pic(-I). Therefore, another plot was tried for the 18C6 and B18C6 extraction into $\mathrm{DCE}$ and the $\mathrm{B} 15 \mathrm{C} 5$ and $\mathrm{B} 18 \mathrm{C} 6$ one into $\mathrm{NB}$. 
Table 1. Various equilibrium constants for the NaPic extraction with L into DCM, DCE and NB at $298 \mathrm{~K}$

\begin{tabular}{|c|c|c|c|c|c|c|}
\hline $\begin{array}{l}\text { Diluents } \\
\left(\varepsilon_{\mathrm{r}}\right)^{a}\end{array}$ & $\mathrm{~L}$ & $\log K_{\mathrm{ex} \pm}^{b}$ & $\log K_{\mathrm{ex}}^{b, c}$ & $\begin{array}{l}\log K_{\mathrm{D}, \mathrm{Pic}}{ }^{c} \\
(I)^{d}\end{array}$ & $\begin{array}{l}\log K_{1, \mathrm{org}}{ }^{e} \\
\left(I_{\text {org }}\right)^{d}\end{array}$ & $\log K_{\mathrm{ML}, \mathrm{org}} f$ \\
\hline org $=\mathrm{DCM}$ & $15 \mathrm{C} 5$ & $-1.7_{6} \pm 0.3_{0}$ & $\begin{array}{l}4.391 \pm 0.008 \\
4.37 \pm 0.02^{b}\end{array}$ & $\begin{array}{l}-2.8_{6} \pm 0.1_{4} \\
(0.0059)\end{array}$ & $\begin{array}{l}6.2 \pm 0.3 \\
\left(3.0 \times 10^{-6}\right)\end{array}$ & $4.6_{5}$ \\
\hline \multirow[t]{3}{*}{$(8.93)$} & $\mathrm{B} 15 \mathrm{C} 5$ & $-2.9_{9} \pm 0.2_{5}$ & $\begin{array}{l}3.642 \pm 0.003 \\
3.632 \pm 0.005^{b}\end{array}$ & $\begin{array}{l}-3.3_{5} \pm 0.1_{4} \\
(0.019)\end{array}$ & $\begin{array}{l}6.6 \pm 0.2 \\
\left(2.3 \times 10^{-6}\right)\end{array}$ & $3.4_{2}$ \\
\hline & $18 \mathrm{C} 6$ & $-0.99 \pm 0.04$ & $\begin{array}{l}3.738 \pm 0.002 \\
3.680 \pm 0.005^{b}\end{array}$ & $\begin{array}{l}-1.89 \pm 0.02 \\
(0.0060)\end{array}$ & $\begin{array}{l}4.73 \pm 0.04 \\
\left(3.0 \times 10^{-5}\right), 4.0^{j}, 4.5^{j}\end{array}$ & 5.42 \\
\hline & B18C6 & $-2.20 \pm 0.05$ & $\begin{array}{l}3.43 \pm 0.01 \\
3.365 \pm 0.009^{b}\end{array}$ & $\begin{array}{l}-3.11 \pm 0.05 \\
(0.040)\end{array}$ & $\begin{array}{l}5.63 \pm 0.05 \\
\left(2.6 \times 10^{-6}\right)\end{array}$ & 4.21 \\
\hline \multirow[t]{4}{*}{$\begin{array}{l}\text { DCE } \\
(10.36)\end{array}$} & $15 \mathrm{C} 5$ & $-1.8_{7} \pm 0.2_{1}$ & $\begin{array}{l}4.611 \pm 0.008 \\
4.59 \pm 0.01^{b}\end{array}$ & $\begin{array}{l}-2.90 \pm 0.08 \\
(0.0070)\end{array}$ & $\begin{array}{l}6.5 \pm 0.2 \\
\left(1.7 \times 10^{-6}\right)\end{array}$ & $5.2_{3}$ \\
\hline & B15C5 & $-3.0 \pm 1.4$ & $\begin{array}{l}3.74 \pm 0.01 \\
3.74 \pm 0.03^{b}\end{array}$ & $\begin{array}{l}-3.3_{4} \pm 0.6_{6} \\
(0.020)\end{array}$ & $\begin{array}{l}6.8 \pm 1.4 \\
\left(2.4 \times 10^{-6}\right)\end{array}$ & 4.1 \\
\hline & $18 \mathrm{C} 6$ & $0.16 \pm 0.07,-0.63^{k}$ & $\begin{array}{l}3.59 \pm 0.02 \\
3.0_{3} \pm 0.1_{6}^{b}, 3.44^{l}\end{array}$ & $\begin{array}{l}-1.38 \pm 0.04 \\
(0.0062)\end{array}$ & $\begin{array}{l}3.43 \pm 0.08 \\
\left(1.0 \times 10^{-4}\right), 4.07^{k}\end{array}$ & 7.26 \\
\hline & B18C6 & $-1.05 \pm 0.03,-0.91^{k}$ & $\begin{array}{l}3.528 \pm 0.009 \\
3.425 \pm 0.006^{b}, 3.47^{l}\end{array}$ & $\begin{array}{l}-2.32 \pm 0.05 \\
(0.053)\end{array}$ & $\begin{array}{l}4.58 \pm 0.03 \\
\left(8.9 \times 10^{-6}\right), 4.38^{k}\end{array}$ & 6.05 \\
\hline \multirow[t]{4}{*}{$\begin{array}{l}\text { NB } \\
(35.6)^{m}\end{array}$} & $15 \mathrm{C} 5$ & $\begin{array}{l}1.3_{6} \pm 0.3_{2} \\
2.0^{n}, 2.1^{n}\end{array}$ & $\begin{array}{l}6.69 \pm 0.05 \\
6.5_{1} \pm 0.1{ }_{5}^{b}\end{array}$ & $\begin{array}{l}-2.0_{3} \pm 0.1_{6} \\
(0.00033)\end{array}$ & $\begin{array}{l}5.3 \pm 0.3 \\
\left(3.1 \times 10^{-6}\right)\end{array}$ & $6.5,7.1_{4}^{p}$ \\
\hline & B15C5 & $\begin{array}{l}1.1_{1} \pm 0.2_{6} \\
1.0^{n}\end{array}$ & $5.3_{0} \pm 0.1_{3}^{q}$ & $\begin{array}{l}-0.3_{5} \pm 0.1_{1} \\
(0.00026)\end{array}$ & $\begin{array}{l}4.1_{9} \pm 0.2_{9} \\
\left(9.3 \times 10^{-5}\right)\end{array}$ & $6.2_{4}, 6.1_{0}^{p}$ \\
\hline & $18 \mathrm{C} 6$ & $\begin{array}{l}1.5_{1} \pm 0.4_{8} \\
2.6^{n}, 2.8^{n}\end{array}$ & $\begin{array}{l}7.19 \pm 0.07 \\
7.0_{2} \pm 0.1_{6}^{b}\end{array}$ & $\begin{array}{l}-2.5_{0} \pm 0.3_{9} \\
(0.00033)\end{array}$ & $\begin{array}{l}5.7 \pm 0.5 \\
\left(1.0 \times 10^{-6}\right)\end{array}$ & $6.6,7.7^{p}$ \\
\hline & B18C6 & $\begin{array}{l}1.8_{7} \pm 0.1_{6} \\
2.0^{n}\end{array}$ & $\begin{array}{l}6.3_{0} \pm 0.1_{0} \\
5.4_{5} \pm 0.8_{9}{ }^{b}\end{array}$ & $\begin{array}{l}-1.6_{1} \pm 0.1_{0} \\
(0.00033)\end{array}$ & $\begin{array}{l}4.4 \pm 0.2 \\
\left(7.9 \times 10^{-6}\right)\end{array}$ & $7.0,7.0_{9}^{p}$ \\
\hline
\end{tabular}

Table 1. (continued)

\begin{tabular}{lllll}
\hline $\begin{array}{l}\text { Diluents } \\
\left(\mathcal{E}_{\mathrm{r}}\right)^{a}\end{array}$ & $\mathrm{~L}$ & $\log {K_{\mathrm{D}, \mathrm{Na}}}^{g}$ & $\log K_{1}^{b}$ & $\log K_{\mathrm{D}, \mathrm{L}}{ }^{h}$ \\
\hline DCM & 15C5 5 & $-3.55^{i}$ & 1.463 & 0.64 \\
& B15C5 & $-3.06^{i}$ & 2.600 & 2.422 \\
& 18C6 & $-4.52^{i}$ & 1.723 & 0.60 \\
& B18C6 & $-3.30^{i}$ & 2.68 & 2.52 \\
\hline DCE & 15C5 & -4.20 & 1.46 & 0.02 \\
& B15C5 & -3.76 & 2.598 & 1.910 \\
& 18C6 & -5.72 & 1.722 & 0.03 \\
& B18C6 & -4.78 & 2.67 & 2.009 \\
\hline NB & 15C5 & $-3.10,-3.75^{\circ}$ & 1.51 & -0.66 \\
& B15C5 & $-4.78,-4.64^{o}$ & 2.70 & 1.6 \\
& 18C6 & $-2.63,-3.69^{o}$ & 1.77 & -1.00 \\
& B18C6 & $-3.52,-3.61^{\circ}$ & 2.78 & 1.57 \\
\hline
\end{tabular}

${ }^{a}$ Dielectric constants of pure solvents at 298 K. See Refs. Lide, 1995; Takeda, 2002. ${ }^{b}$ Values obtained from the plots of $\log K_{\mathrm{ex}}{ }^{\mathrm{mix}} v s .-(1 / 2) \log P$. In addition to these data, the $K_{\mathrm{ex}} \& K_{1}$ values have been published in supplementary materials of Ref. Kudo et al., 2016a. ${ }^{c}$ Values obtained from the plots of $\log K_{\mathrm{ex}}{ }^{\mathrm{mix}} v s .-\log \left(\left[\mathrm{Na}{ }^{+}\right][\mathrm{L}]_{\text {org }}\right){ }^{d}$ Ionic strength value, $I$ or $I_{\text {org }}$, which was averaged for the water or org phase. ${ }^{e}$ Values calculated from the relation $\log K_{1, \mathrm{org}}=\log \left(K_{\mathrm{ex}}{ }^{c} / K_{\mathrm{ex} \pm}\right)$. ${ }^{f}$ Values calculated from the relation $\log K_{\mathrm{NaL}, \text { org }}=\log K_{\mathrm{ex} \pm}-\log K_{\mathrm{D}, \mathrm{Na}} \cdot K_{\mathrm{D}, \text { Pic }} \cdot{ }^{g}$ Values calculated from the equation $\log$ $K_{\mathrm{D}, \mathrm{Na}}=\left(\Delta \phi_{\mathrm{eq}}-\Delta \phi_{\mathrm{Na}}{ }^{0 \prime}\right) / 0.05916=\Delta \phi_{\mathrm{eq}} / 0.05916+\log K_{\mathrm{D}, \mathrm{Na}}{ }^{\mathrm{s}}$ at $298 \mathrm{~K}$. ${ }^{h}$ Refs. Iwachido et al., 1982 ; Iwachido et al., 1977. ${ }^{i}$ Values estimated from $\Delta \phi_{\mathrm{Na}}{ }^{\prime \prime}=0.33$, V. See the section 3.7 in the text. ${ }^{j}$ Ref. Kolthoff, $1981 .{ }^{k}$ See Ref. Kikuchi \& Sakamoto, 2000. ${ }^{l}$ The $\log K_{\mathrm{ex}}$ values were calculated from the relation in the footnote $e .{ }^{m}$ Values at $293 \mathrm{~K}$. See Ref. Lide, 1995. ${ }^{n}$ Ref. Kudo et al., 2012. ${ }^{o}$ Values calculated from the $K_{\mathrm{NaL}, \mathrm{NB}}$ ones polarographically-determined, using the common logarithmic form of Eq. (5). See the footnote $n .{ }^{p}$ Values at $I_{\mathrm{NB}}=0.05 \mathrm{~mol} \mathrm{dm}{ }^{-3}\left(\mathrm{Bu}_{4} \mathrm{~N}^{+} \mathrm{BPh}_{4}{ }^{-}\right)$. See Ref. Kudo et al., 2012. ${ }^{q}$ Values obtained from an average $\&$ its standard deviation of several experimental $K_{\text {ex }}{ }^{\text {mix }}$ values. 


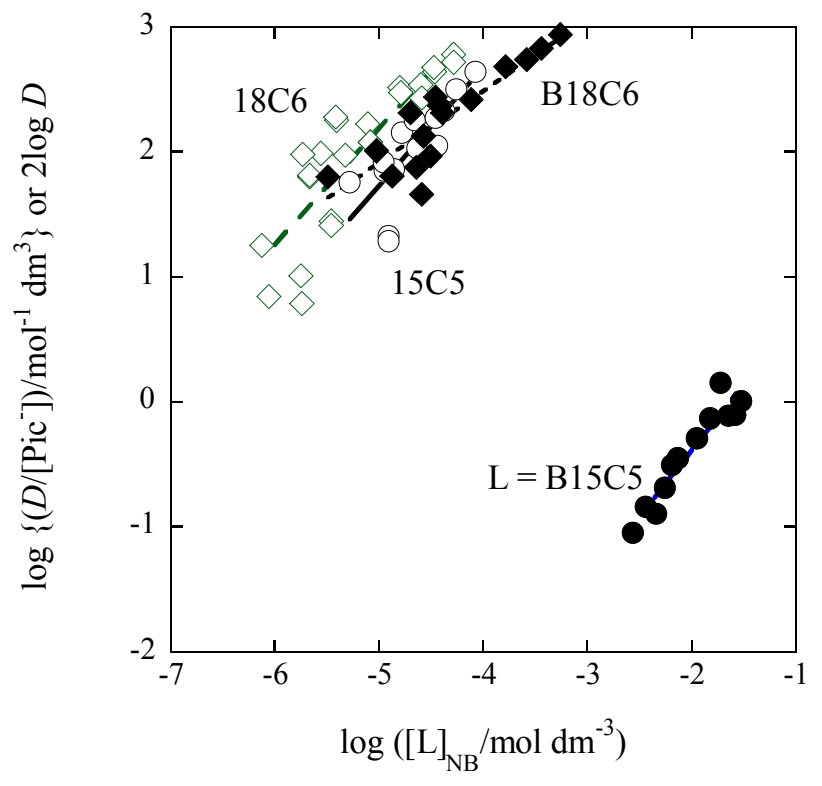

Figure 1. Plots of $\log \left(D /\left[\mathrm{Pic}^{-}\right]\right)$or $2 \log D v s . \log [\mathrm{L}]_{\mathrm{NB}}$. The $y$ axis of the $\mathrm{B} 15 \mathrm{C} 5$ system is $2 \log D$. The slope for the B18C6 (= L) system was less than 0.90

From the above result, the composition of the $\mathrm{B} 15 \mathrm{C} 5$ extraction system into NB was determined by employing the plot of $2 \log D_{\mathrm{Na}}$ versus $\log [\mathrm{L}]_{\text {org }}$ (see Appendix B) (Kudo et al., 2011a). Its slope $\left(a^{\prime}\right)$ and intercept $\left(b^{\prime}\right)$ were 1.05 and 1.71, respectively (Fig. 1). Here, the $b^{\prime}$ value corresponds to the $\log K_{\text {ext }}$ one (Kudo et al., 2011a). Similarly, the compositions and the apparent $\log K_{\mathrm{ex} \pm}$ values were $a^{\prime}=1.06$ and $b^{\prime}=2.19$ for the B18C6 extraction-system into NB, 1.08 and 0.34 for the $18 \mathrm{C} 6$ one and 0.98 and -1.12 for the B18C6 one into DCE, respectively. These $a^{\prime}$ values in the $2 \log D_{\mathrm{Na}}$ plots consequently showed mainly the extraction of the species with the $\mathrm{Na}(\mathrm{I})$ : L composition of 1:1 (Kudo et al., 2011a), that is, the distribution of $\mathrm{NaL}^{+}$into the org phase with $\mathrm{Pic}^{-}$as a conuter anion.

Thus, the extraction of NaLPic or $\mathrm{NaL}^{+}$with $\mathrm{Pic}^{-}$were proved in all the extraction systems. Next, we determined the $K_{\mathrm{D}, \mathrm{A}}$ values (Kudo \& Takeuchi, 2014; Kudo \& Katsuta, 2015; Kudo et al., 2016; Kudo et al., 2014; Kudo et al., 2015; Kudo et al., 2011a), together with the $K_{\text {ex }}$ ones, by using the relation of

$$
\log K_{\mathrm{ex}}{ }^{\mathrm{mix}} \approx \log \left\{K_{\mathrm{ex}}+\left(K_{\mathrm{D}, \mathrm{A}} /\left[\mathrm{M}^{+}\right][\mathrm{L}]_{\mathrm{org}}\right)\right\} .
$$

Here, $K_{\text {ex }}{ }^{m i x}$ (see the section 2.3 for its definition) nearly equals ([MLA $\left.]_{\text {org }}+\left[\mathrm{ML}^{+}\right]_{\text {org }}\right) / P$ (see the introduction for $P$ ) with the charge balance equation,

$$
\left[\mathrm{ML}^{+}\right]_{\text {org }}+\left[\mathrm{M}^{+}\right]_{\text {org }}=\left[\mathrm{A}^{-}\right]_{\text {org }}
$$

for the org phase. Figure 2 shows examples of the plots for the $15 \mathrm{C} 5$ and B18C6 extraction into NB. The thus-obtained $\log K_{\text {ex }}$ values were in agreement with the values (Takeda \& Takagi, 1994; Takeda et al., 1995; Takeda et al., 1998; Takeda et al., 2002) reported before in figures, except for the $18 \mathrm{C} 6$ extraction into DCE $\left\{\log K_{\mathrm{ex}}=4.13\right.$ (Takeda et al., 1998)\}. For the NB extraction system with $\mathrm{Pic}^{-}$and L, we were not able to find out suitable literature values of $K_{\text {ex }}$.

Also, the $K_{\text {ex }}$ values have been determined from the other modified form of Eq. (1),

$$
\log K_{\mathrm{ex}}^{\text {mix }} \approx \log \left\{K_{\mathrm{ex}}+\left(K_{\mathrm{ex} \pm} / P\right)^{1 / 2}\right\}
$$

under the approximate electroneutrality condition (Kudo \& Takeuchi, 2014; Kudo \& Katsuta, 2015; Kudo et al., 2016; Kudo et al., 2014; Kudo et al., 2015; Kudo et al., 2011a) of $\left[\mathrm{ML}^{+}\right]_{\mathrm{org}} \approx\left[\mathrm{A}^{-}\right]_{\mathrm{org}}$ that comes from the approximation of $\left[\mathrm{ML}^{+}\right]_{\text {org }} \gg\left[\mathrm{M}^{+}\right]_{\text {org }}$ in Eq. (2). In addition to these values, the $K_{1, \text { org }}$ values for given averaged $I_{\text {org }}$ ones were estimated from $K_{\mathrm{ex}} / K_{\mathrm{ex} \pm}\left(=[\mathrm{MLA}]_{\mathrm{org}} /\left[\mathrm{ML}^{+}\right]_{\mathrm{org}}\left[\mathrm{A}^{-}\right]_{\mathrm{org}}\right)($ Kudo \& Takeuchi, 2014; Kudo \& Katsuta, 2015; Kudo et al., 2016; Kudo et al., 2014; Kudo et al., 2015; Kudo et al., 2011a). The thus-obtained values are listed in Table 1. The present $\log K_{\text {ext }}$

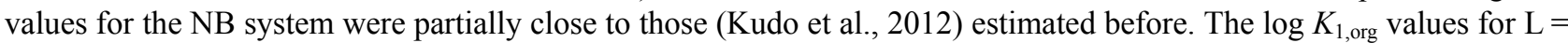
$18 \mathrm{C} 6$ and B18C6 at org = DCE and for 18C6 at DCM were nearly the same as or close to those (Kikuchi \& Sakamoto, 2000; Kolthoff, 1981) (see Table 1) reported previously.

The $\log K_{\text {ex }}$ order was DCM $<\mathrm{DCE}<<\mathrm{NB}$ for $\mathrm{L}=18 \mathrm{C} 6$ and $\mathrm{B} 18 \mathrm{C} 6$, while DCE $<\mathrm{DCM}<<\mathrm{NB}$ for $15 \mathrm{C} 5$ and B15C5 (Table 1). Essentially, these orders seem to reflect that reported by Danesi et al. for the NaPic extraction with dibenzo-18C6 into mixtures between NB and toluene (TE): $\log K_{\text {ex }}=0.28$ for a $30 \% \mathrm{NB}-70 \% \mathrm{TE}$ phase with the 
dielectric constant $\left(\mathcal{E}_{\mathrm{r}}\right)$ of $10.6,0.65$ or 0.79 for $50 \% \mathrm{NB}-50 \% \mathrm{TE}$ with $\mathcal{E}_{\mathrm{r}}$ of 15.6 and 1.78 or 2.03 for $100 \% \mathrm{NB}$ with $\mathcal{E}_{\mathrm{r}}$ of 35.6 at $295 \mathrm{~K}$ (Danesi et al., 1975). An increase in polarity of diluent essentially causes an increase in $\log K_{1, \mathrm{org}}{ }^{-1}$, facilitating the dissociation of $\mathrm{NaL}^{+} \mathrm{Pic}^{-}$in the org phases, except for $\mathrm{L}=18 \mathrm{C} 6$ (see Table 1). Here, the $\mathcal{E}_{\mathrm{r}}$ values of pure DCM, DCE and NB are 8.93, 10.36 at $298 \mathrm{~K}(10.42$ at $293 \mathrm{~K}$ ) and 35.6 at $293 \mathrm{~K}$, respectively (Table 1) (Lide, 1995; Takeda, 2002). The above results indicate that the interaction between $\mathrm{NaL}^{+}$and $\mathrm{Pic}^{-}$in the org phase is mainly electrostatic, although the diluents are saturated with water, as described next.

According to Refs. Iwachido et al., 1982; Iwachido et al., 1977; Kikuchi et al., 2001, mole fractions $\left(f_{\mathrm{w}}\right)$ or molar concentrations of water dissolved in their diluents have been reported to be $f_{\mathrm{w}}=0.0078$ or $\left[\mathrm{H}_{2} \mathrm{O}\right]_{\text {org }}=0.128 \mathrm{~mol} \mathrm{dm}^{-3}$ for org $=\mathrm{DCM}, 0.0082$ or 0.127 for DCE and 0.0149 or 0.178 for NB. These $f_{\mathrm{w}}$ values were approximately reduced to $\left[\mathrm{H}_{2} \mathrm{O}\right]_{\text {DCM }} \approx 0.12 \mathrm{~mol} \mathrm{dm}{ }^{-3},\left[\mathrm{H}_{2} \mathrm{O}\right]_{\text {DCE }} \approx 0.10$ and $\left[\mathrm{H}_{2} \mathrm{O}\right]_{\mathrm{NB}} \approx 0.148$, respectively. Thus, the $\left[\mathrm{H}_{2} \mathrm{O}\right]_{\text {org }}$ values estimated from the $f_{\mathrm{w}}$ ones (Iwachido et al., 1982) are close to those (Kikuchi et al., 2001) determined experimentally. Obviously, the three $\left[\mathrm{H}_{2} \mathrm{O}\right]_{\text {org }}$ values were much larger than the experimental $[\mathrm{NaLPic}]_{\text {org }}$ and $\left[\mathrm{NaL}^{+}\right]_{\text {org }}$ (or $\left[\mathrm{Pic}^{-}\right]_{\text {org }}$ ) ones.

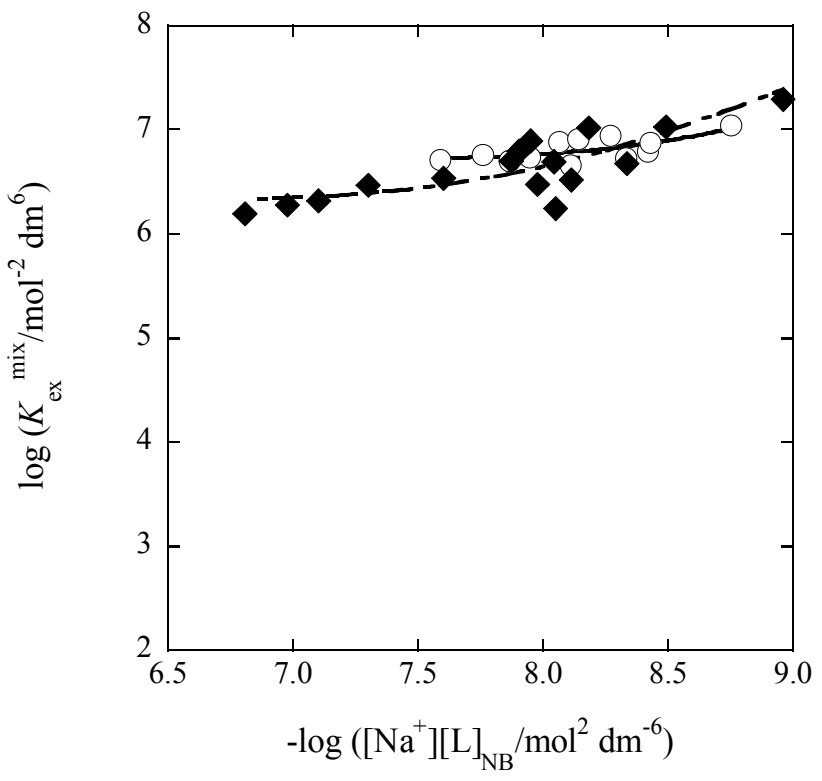

Figure 2. Plots of $\log K_{\text {ex }}{ }^{\text {mix }} v s .-\log \left(\left[\mathrm{Na}^{+}\right][\mathrm{L}]_{\mathrm{NB}}\right)$ for the $15 \mathrm{C} 5(=\mathrm{L})$ and B18C6 extraction systems. Open circles and full diamonds show the plots for the systems with $\mathrm{L}=15 \mathrm{C} 5$ and $\mathrm{B} 18 \mathrm{C} 6$, respectively, and are in accord with the symbols in Fig. 1

\subsection{Trends of the Ion-Pair or Complex Formation in the Org Phases}

In Table 1, the $\log K_{1, \text { org }}$ orders, $18 \mathrm{C} 6<\mathrm{B} 18 \mathrm{C} 6<15 \mathrm{C} 5 \leq \mathrm{B} 15 \mathrm{C} 5$, at org = DCM and DCE can be briefly explained in terms of the combined parameter among the basicity of donor $\mathrm{O}$ atoms (parameter $B$ ), $\mathrm{Na}^{+}$selectivity $\left(M^{\prime}\right)$ and molar volume $(V)$ : see Appendix C (Kudo et al., 2016a) for figures relevant to these parameters. The L's order due to the combined parameter is $18 \mathrm{C} 6$ (sum $\left.=B+M^{\prime}+V=2+0+1=3\right)<\mathrm{B} 18 \mathrm{C} 6(3.8)<15 \mathrm{C} 5(4)<\mathrm{B} 15 \mathrm{C} 5(4.8)$. Thus, the combined parameter, $B+M^{\prime}+V$, reproduces well the above $\log K_{1, \text { org }}$ orders. The parameters of $B \& V$ reflect effects on the benzo-group substitution, while the parameter $M^{\prime}$ does that on a size-fitting of the central $\mathrm{Na}^{+}$to the cavity of $\mathrm{L}$. These agreements suggest that such L's characteristics compositely contribute to the NaLPic formation in the org phase (Kudo et al., 2016a).

However, the above parameter was not held for the $\log K_{1, \mathrm{NB}}$ values. The $\log K_{1, \mathrm{NB}}$ order was B15C5 $\leq \mathrm{B} 18 \mathrm{C} 6<15 \mathrm{C} 5 \leq$ 18C6. The L's order due to the combined parameter, $B+S$, is B15C5 $=\mathrm{B} 18 \mathrm{C} 6(1.8)<15 \mathrm{C} 5=18 \mathrm{C} 6$ (4). The combined parameter, $B+S$, reproduces the $\log K_{1, \mathrm{NB}}$ order. Similarly, the parameter $S$ reflects an effect of flexibility on the L's ring (Kudo et al., 2016a). These facts suggest that the flexibility of $\mathrm{L}$ is dominant for the ion-pair formation in the NB phase. On the other hand, the size effect based on the benzo-group substitution can be dominant for that in the DCM and DCE phases.

The $\log K_{\text {NaL,DCE }}$ order, L $=$ B15C5 $<15 \mathrm{C} 5<$ B18C6 $<18 \mathrm{C} 6$ (see Table 1), can be mainly explained in terms of the combined effect among the flexibility of $\mathrm{L}$ (parameter $S$ ), number of donor $\mathrm{O}$ atoms $(N)$ and cavity size $(C)$. This combined parameter, $C+N+S$, shows the order B15C5 (sum = 7) $<15 \mathrm{C} 5(8)<\mathrm{B} 18 \mathrm{C} 6(9)<18 \mathrm{C} 6(10)$. This order well agreed with the $\log K_{\mathrm{NaL}, \mathrm{DCE}}$ order. Individual relations in this order were B15C5 $<15 \mathrm{C} 5$ and $\mathrm{B} 18 \mathrm{C} 6<18 \mathrm{C} 6$ in the substitution (positive changes in $B \& /$ or $S$ ); $15 \mathrm{C} 5<<18 \mathrm{C} 6$ and $\mathrm{B} 15 \mathrm{C} 5<<\mathrm{B} 18 \mathrm{C} 6$ in the size change (those in $C, N \& /$ or 
$V$ ). Additionally, the parameter $N$ should relate to contribution of the $\mathrm{Na}(\mathrm{I})-\mathrm{O}$ bonds to the $K_{\mathrm{NaL}, \mathrm{DCE}}$ value. The $K_{\mathrm{NaL}, \mathrm{DCE}}$ relation of B18C6 < 18C6 was in accord with that reported before, although the reported values $\left\{10^{9.71} \mathrm{~mol}^{-1} \mathrm{dm}^{3}\right.$ for L $=18 \mathrm{C} 6 \& 10^{9.43}$ for B18C6 at $298 \mathrm{~K}$ (Kikuchi \& Sakamoto, 2000) $\}$ were much larger than the present ones. As well as the $\log K_{\mathrm{NaL}, \mathrm{DCE}}$ order, we can explain the $\log K_{\mathrm{NaL}, \mathrm{DCM}}$ one using the combined parameter, $B+N$ : B15C5 (sum $\left.=5.8\right)<$ B18C6 (6.8) < 15C5 (7) < 18C6 (8).

Using the combined parameter, $C+N+S$, the same discussion can be essentially true of the $\log K_{\mathrm{NaL}, \mathrm{NB}}$ values, except for the relation 18C6 $\leq \mathrm{B} 18 \mathrm{C} 6$. The $K_{\mathrm{NaL}, \mathrm{NB}}$ values (Kudo et al., 2012) reported by ion-transfer polarographic measurements were close to or somewhat larger than the values determined here (see Table 1). This $\log K_{\mathrm{NaL,NB}}$ order is well reflected by the parameter, $C+N+S$.

\subsection{Determination of $\Delta \phi_{e q}$ and a Consideration for Its Content}

According to the previous papers (Kudo \& Katsuta, 2015; Kudo et al., 2016; Markin \& Volkov, 1989), an approximate value of $\Delta \phi_{\mathrm{eq}}$ has been obtained from comparing the experimental $0.05916 \times \log K_{\mathrm{D}, \mathrm{A}}$ value with a standard formal potential $\left(\Delta \phi_{\mathrm{A}}{ }^{\prime \prime}\right)$ by using the following equation:

$$
\Delta \phi_{\mathrm{eq}}=\Delta \phi_{\mathrm{A}}{ }^{\prime \prime}-(R T / F) \ln K_{\mathrm{D}, \mathrm{A}}=-0.05916 \times\left(\log K_{\mathrm{D}, \mathrm{A}}-\log K_{\mathrm{D}, \mathrm{A}}^{\mathrm{S}}\right)
$$

in a V unit at $298 \mathrm{~K}$. Here, the $\Delta \phi_{\mathrm{A}}{ }^{0 \prime}$ value is available from Refs. Kudo \& Katsuta, 2015; Markin \& Volkov, 1989; Kudo et al., 2011 (see the section 3.6) and the $K_{\mathrm{D}, \mathrm{A}}$ one is determined experimentally (see the section $3.1 \&$ Table 1 ). The $\Delta \phi_{\text {Pic }}{ }^{\prime \prime}$ values are $-0.040 \mathrm{~V}$ at the water/DCM interface (Danil de Namor et al., 1989), -0.0598 at the water/DCE one (Kudo et al., 2011) and 0.0030 at the water/NB one (Kudo et al., 2011). Table 2 summarizes the thus-obtained $\Delta \phi_{\mathrm{eq}}$ values. Also, the same values were calculated from an equation \{see Eq. (6) below\} which was derived from Eq. (2) with Eq. (3) (Kudo \& Katsuta, 2015; Takeda et al., 1995a) and then they were symbolized as $\Delta \phi_{\text {eq,cb. }}$

Table 2. Comparison of $\Delta \phi_{\mathrm{eq}}$ values estimated from the $K_{\mathrm{D} \text {,Pic }}$ values ${ }^{a}$ with those from the charge balance equation ${ }^{b}$ for the NaPic extraction with L into DCM, DCE and NB at $298 \mathrm{~K}$

\begin{tabular}{lllll}
\hline & \multicolumn{4}{c}{$\Delta \phi_{\mathrm{eq}}{ }^{a}\left(\Delta \phi_{\mathrm{eq}, \mathrm{cc}}\right)^{b} / \mathrm{V}$} \\
\cline { 2 - 5 } Diluent & $\mathrm{L}=15 \mathrm{C} 5$ & $\mathrm{~B} 15 \mathrm{C} 5$ & $18 \mathrm{C} 6$ & $\mathrm{~B} 18 \mathrm{C} 6$ \\
\hline DCM & $0.1_{3}$ & $0.1_{6}$ & 0.071 & 0.14 \\
& $(0.104 \pm 0.005)$ & $(0.126 \pm 0.003)$ & $(0.073 \pm 0.006)$ & $(0.113 \pm 0.004)$ \\
\hline DCE & 0.11 & $0.1_{4}$ & 0.022 & 0.078 \\
& $\left(0.09_{2} \pm 0.02_{0}\right)$ & $(0.100 \pm 0.008)$ & $\left(0.01_{3} \pm 0.01_{6}\right)$ & $\left(0.05_{1} \pm 0.01_{7}\right)$ \\
\hline NB & $0.1_{2}, 0.08^{c}$ & $0.024,0.035^{c}$ & $0.1_{5}, 0.092^{c}$ & $0.09_{8}, 0.096^{c}$ \\
& $(0.124 \pm 0.007)$ & $\left(0.02_{6} \pm 0.01_{5}\right)$ & $\left(0.10_{6} \pm 0.01_{8}\right)$ & $\left(0.11_{2} \pm 0.04_{2}\right)$ \\
\hline
\end{tabular}

${ }^{a}$ The $\Delta \phi_{\text {eq }}$ data have been published in the supplementary materials of Ref. Kudo et al., 2016a. ${ }^{b}$ The $\Delta \phi_{\text {eq }}$ values calculated from the charge balance equation, Eq. (2) or (6). ${ }^{c}$ The $\Delta \phi_{\mathrm{eq}}$ values calculated from the equation, $\Delta \phi_{\mathrm{eq}}=\Delta \phi_{\mathrm{Na}}{ }^{0}$ $+0.05916 \times \log K_{\mathrm{D}, \mathrm{Na}}$, with the $\log K_{\mathrm{D}, \mathrm{Na}}$ values of the footnote $g$ in Table 1.

For the B18C6-DCM and -DCE systems, the $\Delta \phi_{\mathrm{eq}}$ values based on the $K_{\mathrm{D}, \mathrm{Pic}}$ values were different from the $\Delta \phi_{\mathrm{eq}, \mathrm{cb}}$ ones based on the charge balance $(\mathrm{cb})$ equations over experimental errors. The same may be true of the 15C5-NB system based on the $K_{\mathrm{D}, \mathrm{Na}}$ value (see the footnote $b$ in Table 2). On the other hand, the former values were in accord with the latter ones for the other systems. These tendencies were in agreement with those (Kudo \& Takeuchi, 2014) reported before for the extraction of alkaline-earth metal picrates by $18 \mathrm{C} 6$ or B18C6. The $\Delta \phi_{\text {eq }}$ orders, obtained from the $K_{\mathrm{D}, \text { Pic }}$ values, were

$$
\begin{aligned}
& 18 \mathrm{C} 6<15 \mathrm{C} 6<\mathrm{B} 18 \mathrm{C} 6<\mathrm{B} 15 \mathrm{C} 5 \text { for the DCM system, } \\
& 18 \mathrm{C} 6<\mathrm{B} 18 \mathrm{C} 6<15 \mathrm{C} 5<\mathrm{B} 15 \mathrm{C} 5 \text { for DCE and } \\
& \mathrm{B} 15 \mathrm{C} 5<\mathrm{B} 18 \mathrm{C} 6<15 \mathrm{C} 5<18 \mathrm{C} 6 \text { for NB. }
\end{aligned}
$$

Also, the $\Delta \phi_{\text {eq,cb }}$ orders were

$$
\begin{aligned}
& 18 \mathrm{C} 6<15 \mathrm{C} 5<\mathrm{B} 18 \mathrm{C} 6<\mathrm{B} 15 \mathrm{C} 5 \text { for DCM, } \\
& 18 \mathrm{C} 6<\mathrm{B} 18 \mathrm{C} 6<15 \mathrm{C} 5 \leq \mathrm{B} 15 \mathrm{C} 5 \text { for DCE and } \\
& \mathrm{B} 15 \mathrm{C} 5<18 \mathrm{C} 6 \leq \mathrm{B} 18 \mathrm{C} 6 \leq 15 \mathrm{C} 5 \text { for NB. }
\end{aligned}
$$

Except for a position of $18 \mathrm{C} 6$ in the dep order of the NB systems, both orders agreed with each other. Furthermore, the $\Delta \phi_{\text {eq }}$ values which were calculated from the $\log K_{\mathrm{D}, \mathrm{Na}}$ values due to the footnote $o$ in Table 1 were in the order $\mathrm{L}=$ $\mathrm{B} 15 \mathrm{C} 5 \leq 18 \mathrm{C} 6 \leq \mathrm{B} 18 \mathrm{C} 6<15 \mathrm{C} 5$ for the NB system, agreeing with the $\Delta \phi_{\mathrm{eq}, \mathrm{cb}}$ order. Essentially, the above results indicate that the $\Delta \phi_{\mathrm{eq}}$ values, determined approximately, reflect the $\Delta \phi_{\mathrm{eq}, \mathrm{cb}}$ ones. One can see intuitively that the $\Delta \phi_{\mathrm{eq}, \mathrm{cb}}$ values are more-precisely calculated from the extraction experiments (Kudo \& Katsuta, 2015). 


\subsection{Distribution Constants of the Neutral Ion-Pair Complexes into the Org Phases}

The distribution constants $\left(K_{\mathrm{D}, \mathrm{MLA}}\right)$ of $\mathrm{NaLPic}^{0}$ into the org phases were calculated from a thermodynamic relation (Kudo et al., 2016):

$\log K_{\mathrm{ex}}=\log \left(K_{\mathrm{ML}} \cdot K_{1} / K_{\mathrm{D}, \mathrm{L}}\right)+\log K_{\mathrm{D}, \mathrm{MLA}}$,

where the symbols $K_{\mathrm{ML}}, K_{1}$ and $K_{\mathrm{D}, \mathrm{L}}$ refer to the complex formation constant, the ion-pair formation one in water and the distribution constant of $\mathrm{L}$ into the org phase, respectively. The $\log \left(K_{\mathrm{NaL}} / \mathrm{mol}^{-1} \mathrm{dm}^{3}\right)$ values at $298 \mathrm{~K}$ have been reported to be 0.70 for $\mathrm{L}=15 \mathrm{C} 5,0.45$ for $\mathrm{B} 15 \mathrm{C} 5,0.73$ for $18 \mathrm{C} 6$ and 0.81 for B18C6 (Katsuta \& Takeda, 2003) and also the $\log K_{\mathrm{D}, \mathrm{L}}$ values which are available in Refs. Kudo et al., 2011a \& Iwachido et al., 1982 are listed in Table 1. Moreover, Table 1 summarizes the $\log K_{1}$ values which were calculated from the $\log K_{1}^{0}\left(\log K_{1}\right.$ at $\left.I \rightarrow 0\right)$ values with the averaged $I$ values. From the above data, the $\log K_{\mathrm{D}, \mathrm{NaLPic}}$ values were evaluated as follows:

2.87 for $\mathrm{L}=15 \mathrm{C} 5,3.01$ for $\mathrm{B} 15 \mathrm{C} 5,1.88$ for $18 \mathrm{C} 6$ and 2.47 for $\mathrm{B} 18 \mathrm{C} 6$ in the $\mathrm{DCM}$ system;

\subsection{7 for $15 \mathrm{C} 5,2.61$ for B15C5, 1.16 for $18 \mathrm{C} 6$ and 2.06 for B18C6 in DCE;}

3.82 for $15 \mathrm{C} 5,3.75$ for B15C5, 3.68 for $18 \mathrm{C} 6$ and 3.71 for B18C6 in NB (Kudo et al., 2016a).

These $\log K_{\mathrm{D}, \mathrm{NaLPic}}$ orders were $18 \mathrm{C} 6<\mathrm{B} 18 \mathrm{C} 6<15 \mathrm{C} 5<\mathrm{B} 15 \mathrm{C} 5$ at DCM and DCE and $18 \mathrm{C} 6 \leq \mathrm{B} 18 \mathrm{C} 6 \leq \mathrm{B} 15 \mathrm{C} 5<$ $15 \mathrm{C} 5$ at NB. It is interesting that the $\log K_{\mathrm{D}, \mathrm{NaLPic}}$ orders at the former two diluents is the same as that predicted from the combined parameter of $B+M^{\prime}+V$ : see the section 3.2. In addition to $B+M^{\prime}+V$, the order at NB can suggest a contribution of the parameter $S$ to the $15 \mathrm{C} 5$ derivatives in particular.

\subsection{On the Simple Evaluation of the Complexation-Ability of $L$ Based on $K_{e x \pm}$}

When the salt MA is fixed, from the thermodynamic relation (Kudo et al., 2012)

$$
K_{\mathrm{ex} \pm}=K_{\mathrm{D}, \mathrm{M}} \cdot K_{\mathrm{D}, \mathrm{A}} \cdot K_{\mathrm{ML}, \text { org }}
$$

it is obvious that the magnitude of $\log K_{\mathrm{ML}, \mathrm{org}}^{\mathrm{S}}$ ( $=\log K_{\mathrm{ML}, \mathrm{org}}$ at $\Delta \phi_{\mathrm{eq}}=0 \mathrm{~V}$, see the section 3.6) is directly reflected to

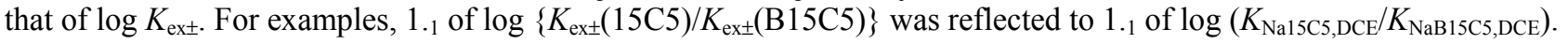
Similarly, $-2.0_{3}$ of $\log \left\{K_{\mathrm{ex} \pm}(15 \mathrm{C} 5) / K_{\mathrm{ex} \pm}(18 \mathrm{C} 6)\right\}$ to $-2.0_{3}$ of $\log \left(K_{\mathrm{Na} 15 \mathrm{C} 5, \mathrm{DCE}} /-K_{\mathrm{Na} 18 \mathrm{C} 6, \mathrm{DCE}}\right)$. Additionally, $-1.5_{2} \pm 0.4_{3}$ of $\log \left\{K_{\text {ext }}(\mathrm{B} 15 \mathrm{C} 5) / K_{\text {ext }}(\mathrm{B} 18 \mathrm{C} 6)\right\}$ for the $\mathrm{NaMnO}_{4}$ extraction with B15C5 and B18C6 into DCE corresponds to $-2{ }_{0}$ of $\log \left(K_{\mathrm{NaB} 15 \mathrm{C} 5, \mathrm{DCE}} / K_{\mathrm{NaB} 18 \mathrm{CC}, \mathrm{DCE}}\right)$ in this study; $-1.5_{2}\left(=\log K_{\mathrm{NaB} 15 \mathrm{C} 5, \mathrm{DCE}}-\log K_{\mathrm{NaB} 18 \mathrm{C} 6, \mathrm{DCE}}=5.6_{7}-7.1_{9}\right)$ which was re-calculated from the $K_{\mathrm{D}, \mathrm{MnO} 4}, K_{\mathrm{D}, \mathrm{Na}}$, and $K_{\mathrm{ex} \pm}$ values in Refs. Kudo et al., $2011 \&$ Kudo et al., 2011a. The both values agreed with each other within the experimental errors. The above analysis based on Eq. (5) can more simplify an evaluation of the complexation-ability of L in the DCE phase saturated with water. The same is basically true of the DCM and NB extraction systems. In particular, the relation like Eq. (5) becomes important for the extraction systems with polar diluents.

\subsection{Correlation of $\log K_{\text {ext }}$ with $-\Delta \phi_{\text {eq }}$}

According to the previous paper (Kudo et al., 2014), the extraction constants for the $\mathrm{M}^{+} \mathrm{A}^{-}$extraction with $\mathrm{L}$ were resolved into

$$
K_{\mathrm{ex}}=K_{\mathrm{D}, \mathrm{M}} \cdot K_{\mathrm{D}, \mathrm{A}} \cdot K_{\mathrm{ML}, \mathrm{org}} \cdot K_{1, \mathrm{org}}=K_{\mathrm{ex} \pm} \cdot K_{1, \mathrm{org}}
$$

and Eq. (5) on the basis of their thermodynamic cycles. Here, $K_{\mathrm{D}, \mathrm{M}}$ is electrochemically expressed as $\exp \left\{\left(\Delta \phi_{\mathrm{eq}}-\right.\right.$ $\left.\Delta \phi_{\mathrm{M}}{ }^{\prime \prime}\right) / 0.02569$ \} at $298 \mathrm{~K}$ (Kudo \& Katsuta, 2015; Kudo et al., 2016; Kudo et al., 2014; Kudo, 2015) and the other constants mean the values standardized at $\Delta \phi_{\mathrm{eq}}=0 \mathrm{~V}$, except for $K_{\mathrm{D}, \mathrm{A}}\left\{\right.$ see Eq. (3)\}. Namely, $K_{\mathrm{ex}} \mathrm{S}$ equals $K_{\mathrm{ex}}$ and $K_{\mathrm{ML}, \mathrm{org}} \mathrm{S}$ does $K_{\mathrm{ML}, \text { org }}$ (Kudo \& Katsuta, 2015; Kudo et al., 2016; Kudo et al., 2014; Kudo, 2015).

A common logarithmic form of Eq. (4a) is

$$
\begin{gathered}
\log K_{\mathrm{ex}}=\log K_{\mathrm{D}, \mathrm{M}}+\log K_{\mathrm{D}, \mathrm{A}}+\log K_{\mathrm{ML}, \text { org }}+\log K_{1, \text { org }} \\
=\left(\Delta \phi_{\mathrm{eq}}-\Delta \phi_{\mathrm{M}}{ }^{\prime \prime}\right) / 0.05916-\left(\Delta \phi_{\mathrm{eq}}-\Delta \phi_{\mathrm{A}}{ }^{\prime \prime}\right) / 0.05916+\log \left(K_{\mathrm{ML}, \mathrm{org}} \mathrm{s} \cdot K_{1, \text { org }} \mathrm{s}\right) \\
=-\left(\Delta \phi_{\mathrm{M}}{ }^{0 \prime}-\Delta \phi_{\mathrm{A}}{ }^{{ }^{\prime}}\right) / 0.05916+\log \left(K_{\mathrm{ML}, \text { org }}^{\mathrm{s}} \cdot K_{1, \text { org }}^{\mathrm{s}}\right),
\end{gathered}
$$

because the $\Delta \phi_{\text {eq }}$ values must be uniform in the given extraction system (Kudo, 2015; Takeda et al., 1995a) which is expressed by Eq. (4). The term, $-\left(\Delta \phi_{\mathrm{M}}{ }^{0 \prime}-\Delta \phi_{\mathrm{A}}{ }^{\prime \prime}\right) / 0.05916$, in Eq. (4c) equals $\log K_{\mathrm{D}, \mathrm{M}}{ }^{\mathrm{S}}+\log K_{\mathrm{D}, \mathrm{A}}{ }^{\mathrm{S}}$ (Kudo \& Katsuta, 2015; Kudo et al., 2015; Kudo, 2015; Kudo et al., 2016a). Equations (4b) and (4c) also show that an introduction of $K_{\mathrm{D}, \mathrm{M}}$ with $\Delta \phi_{\mathrm{eq}} \neq 0$ in Eq. (4b) gives the $K_{\mathrm{D}, \mathrm{A}}$ value, while that of $K_{\mathrm{D}, \mathrm{M}}{ }_{\mathrm{S}}$ in Eq. (4c) does the $K_{\mathrm{D}, \mathrm{A}}{ }^{\mathrm{S}}$ one (Kudo, 2015), when the other equilibrium constants are available from references.

Similarly, the following relation was derived from Eq. (5) (Kudo \& Katsuta, 2015; Kudo et al., 2016; Kudo, 2015; Kudo et al., 2016a): 


$$
\begin{gathered}
\log K_{\mathrm{ex} \pm}=\left(\Delta \phi_{\mathrm{eq}}-\Delta \phi_{\mathrm{M}}{ }^{\prime \prime}\right) / 0.05916-\left(\Delta \phi_{\mathrm{eq}}-\Delta \phi_{\mathrm{A}}{ }^{\prime \prime}\right) / 0.05916+\log K_{\mathrm{ML}, \mathrm{org}}^{\mathrm{S}} \\
=-\left(\Delta \phi_{\mathrm{M}}{ }^{\prime \prime}-\Delta \phi_{\mathrm{A}}{ }^{\prime \prime}\right) / 0.05916+\log K_{\mathrm{ML}, \mathrm{org}}^{\mathrm{S}} \\
=\log \left(K_{\mathrm{D}, \mathrm{M}}{ }^{\mathrm{S}} \cdot K_{\mathrm{D}, \mathrm{A}}{ }^{\mathrm{S}}\right)+\log K_{\mathrm{ML}, \mathrm{org}} .
\end{gathered}
$$

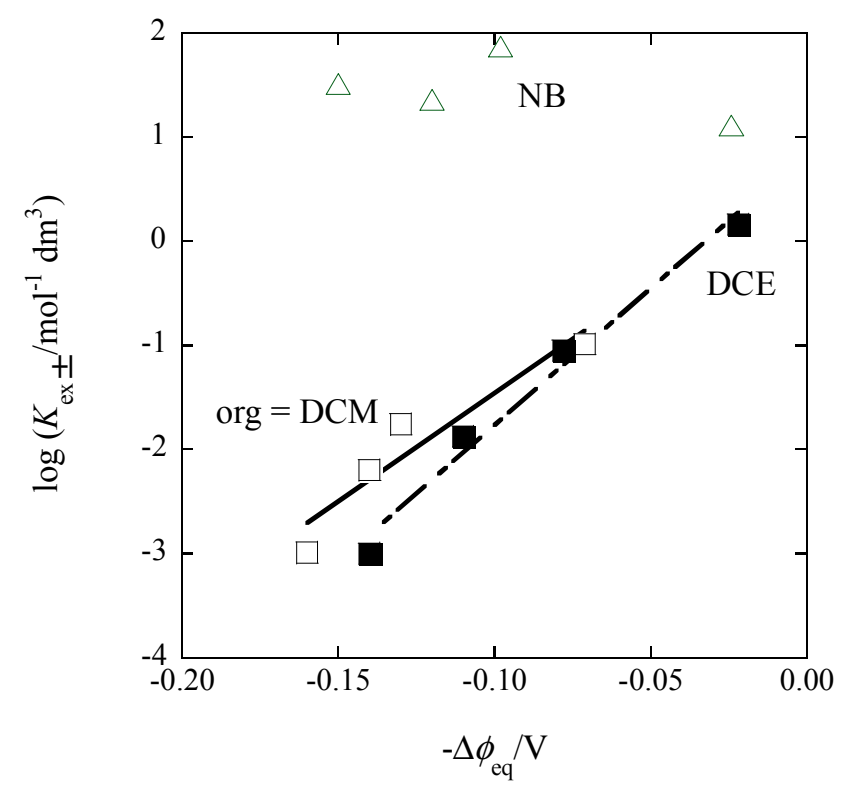

Figure 3. Plots of $\log K_{\mathrm{ex} \pm} v s .-\Delta \phi_{\mathrm{eq}}$ for the three diluents systems composed of the four $\mathrm{L}$. The $\Delta \phi_{\mathrm{eq}}$ values calculated from the experimental $K_{\mathrm{D}, \mathrm{Pic}}$ ones were employed for the $x$ axis

Figure 3 shows plots of $\log K_{\mathrm{ex} \pm}$ versus $-\Delta \phi_{\mathrm{eq}}$ for the NaPic extraction of all employed L into DCM, DCE and NB. The $\log K_{\text {ex } \pm}$ values monotonically increased with an increase in $-\Delta \phi_{\text {eq }}$, except for the NB system. These lines were $a=$ $20.7 \pm 4.9$ and $b=0.6_{1} \pm 0.6_{3}$ at $r=0.948$ for the DCM system and $26_{.2} \pm 2.5$ and $0.8_{5} \pm 0.2_{4}$ at 0.991 for DCE (Fig. 3). These trends can be predicted from the modified Eq. (5a),

$$
\log K_{\text {ext土 }}=16.90\left(-\Delta \phi_{\text {eq }}\right)+\log \left(K_{\mathrm{D}, \mathrm{M}} \cdot K_{\mathrm{ML}, \text { org }}^{\mathrm{s}}\right)+\log K_{\mathrm{D}, \mathrm{A}}^{\mathrm{s}} \text {. }
$$

Here, $16.90 \mathrm{~V}^{-1}$ and the term, $\log \left(K_{\mathrm{D}, \mathrm{M}} \cdot K_{\mathrm{ML}, \mathrm{org}} \mathrm{s}\right)+\log K_{\mathrm{D}, \mathrm{A}} \mathrm{s}$, at $298 \mathrm{~K}$ correspond to slopes and intercepts for the plots, respectively. If differences in $\log \left(K_{\mathrm{D}, \mathrm{M}} \cdot K_{\mathrm{ML}, \mathrm{org}}\right)$ are small among the extraction systems with $\mathrm{L}$, then the plots can become apparently straight lines. The result in Fig. 3 proves that this condition holds approximately for the DCM \& DCE extraction systems at least. The difference between the DCM \& DCE systems and the NB one may be reflecting that in contents between the $\Delta \phi_{\text {eq }}$ values; as an example, $\Delta G_{\text {eq }}=\Delta G_{\text {eq }}$ (charge-dependent) $+\Delta G_{\text {eq }}$ (charge-independent) (Osakai \& Ebina, 1998), where $\Delta G_{\text {eq }}=z F \Delta \phi_{\text {eq }}$. Or we can think that $\Delta G_{\text {ex }}=\Delta G_{\text {ex }}$ (charge-dependent) +

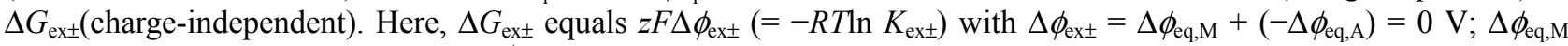
and $\Delta \phi_{\mathrm{eq}, \mathrm{A}}$ refer to dep coming from $\mathrm{M}^{+}$and $\mathrm{A}^{-}$, respectively (Kudo, 2016).

As a more-exact plot (Kudo et al., 2016), we plotted $\log \left(K_{\text {ext }} / K_{\mathrm{D}, \mathrm{Na}}\right)$ against $-\Delta \phi_{\text {eq. }}$. The results were $\log \left(K_{\text {ex }} / K_{\mathrm{D}, \mathrm{Na}}\right)\{=$ $\left.16.90\left(-\Delta \phi_{\mathrm{eq}}\right)+\log \left(K_{\mathrm{D}, \mathrm{A}}^{\mathrm{S}} \cdot K_{\mathrm{ML}, \mathrm{org}} \mathrm{S}\right)\right\}=37.4\left(-\Delta \phi_{\mathrm{eq}}\right)+6.3$ at $r=0.997$ for org $=\mathrm{DCM}$ and $42.9\left(-\Delta \phi_{\mathrm{eq}}\right)+6.9$ at 0.997 for DCE. Both the $r$ values were improved, but the slopes were much larger than the theoretical one $\left(=17 \mathrm{~V}^{-1}\right)$ at $298 \mathrm{~K}$. The latter facts suggest an effect of the deviation of the $\log K_{\mathrm{NaL}, \text { org }}$ values in changing from $\mathrm{L}=15 \mathrm{C} 5$ to $\mathrm{B} 18 \mathrm{C} 6$. The $\log K_{\text {NaL,org }}$ values distributed from 3.4 to 5.42 for org = DCM and from 4 to 7.26 for DCE (see Table 1).

On the other hand, the plots of $\log K_{\text {ex }}$ versus $-\Delta \phi_{\text {eq }}$ for the NaPic extraction of all $\mathrm{L}$ into the same diluents did not show the same correlations as those in Fig. 3. These results suggest that deviations among the $\log K_{1, \text { org }}$ values are large in Eq. (4a). The following results support this suggestion. The $\log K_{1, \text { org }}$ orders were

$$
\begin{aligned}
& 18 \mathrm{C} 6<\mathrm{B} 18 \mathrm{C} 6 \leq 15 \mathrm{C} 5 \leq \mathrm{B} 15 \mathrm{C} 5 \text { for org }=\mathrm{DCM}, \\
& 18 \mathrm{C} 6<\mathrm{B} 18 \mathrm{C} 6<15 \mathrm{C} 5 \leq \mathrm{B} 15 \mathrm{C} 5 \text { for DCE and } \\
& \mathrm{B} 15 \mathrm{C} 5 \leq \mathrm{B} 18 \mathrm{C} 6<15 \mathrm{C} 5 \leq 18 \mathrm{C} 6 \text { for NB (Table } 1) .
\end{aligned}
$$

Maximum differences between the $\log K_{1, \text { org }}$ values were $1.8_{7}$ for DCM, $3_{.3}$ for DCE and $1.5_{1}$ for NB. While, the orders of $16.90\left(-\Delta \phi_{\mathrm{eq}}\right)$ were

$$
\begin{aligned}
& 18 \mathrm{C} 6>15 \mathrm{C} 5 \geq \mathrm{B} 18 \mathrm{C} 6>\mathrm{B} 15 \mathrm{C} 5 \text { for } \mathrm{DCM}, \\
& 18 \mathrm{C} 6>\mathrm{B} 18 \mathrm{C} 6>15 \mathrm{C} 5>\mathrm{B} 15 \mathrm{C} 5 \text { for } \mathrm{DCE} \text { and }
\end{aligned}
$$


$\mathrm{B} 15 \mathrm{C} 5>\mathrm{B} 18 \mathrm{C} 6>15 \mathrm{C} 5>18 \mathrm{C} 6$ for NB.

Due to the reversal in order between the $\log K_{1, \text { org }}$ and $16.90\left(-\Delta \phi_{\mathrm{eq}}\right)$ values, a sum of both values can become roughly a constant in the relation, $\log K_{\mathrm{ex}}=16.90\left(-\Delta \phi_{\mathrm{eq}}\right)+\log \left(K_{\mathrm{D}, \mathrm{M}} \cdot K_{\mathrm{ML}, \text { org }}\right)+\log K_{\mathrm{D}, \mathrm{A}} \mathrm{S}+\log K_{1, \text { org }} \approx \log \left(K_{\mathrm{D}, \mathrm{M}} \cdot K_{\mathrm{ML}, \text { org }}\right)+\log$ $K_{\mathrm{D}, \mathrm{A}} \mathrm{S}+$ constant. The constant terms were in the ranges of 3.20-4.6 for the DCM system, 3.06-5.0 for DCE and 3.1-4.7 for NB. Consequently, the equation becomes $\log K_{\text {ex }} \approx$ constant within \pm 1 .

\subsection{Brief Estimation of Standard Formal Potentials for an Ion Transfer across the Water/Org Solution Interface}

Equation (2) is the charge balance equation for the org phase in the present extraction systems. From the equation, the relation between $K_{\mathrm{D}, \mathrm{M}}$ and $\Delta \phi_{\mathrm{M}}{ }^{0}$ and its same relation as that for $\mathrm{HL}^{+}$(Takeda et al., 1995a), we can easily obtain

$$
\left[\mathrm{M}^{+}\right] \exp \left\{F\left(\Delta \phi_{\mathrm{eq}}-\Delta \phi_{\mathrm{M}^{0}}{ }^{\prime}\right) / R T\right\}+\left[\mathrm{ML}^{+}\right] \exp \left\{F\left(\Delta \phi_{\mathrm{eq}}-\Delta \phi_{\mathrm{ML}}{ }^{0 \prime}\right) / R T\right\}=\left[\mathrm{A}^{-}\right]_{\mathrm{org}},
$$

where $\left[\mathrm{A}^{-}\right]_{\mathrm{org}}\left(=K_{\mathrm{D}, \mathrm{A}}\left[\mathrm{A}^{-}\right]\right)$is practically equal to $I_{\text {org }}$ which is derived from $(1 / 2)\left(\left[\mathrm{M}^{+}\right]_{\mathrm{org}}+\left[\mathrm{ML}^{+}\right]_{\mathrm{org}}+\left[\mathrm{A}^{-}\right]_{\mathrm{org}}\right)$ and Eq. (2). Dividing the both sides of Eq. (6) by $\left[\mathrm{M}^{+}\right]$and rearranging it, the equation becomes

$$
\exp \left\{F\left(\Delta \phi_{\mathrm{eq}}-\Delta \phi_{\mathrm{M}}{ }^{0 \prime}\right) / R T\right\}+\left(K_{\mathrm{ML}}[\mathrm{L}]_{\mathrm{org}} / K_{\mathrm{D}, \mathrm{L}}\right) \exp \left\{F\left(\Delta \phi_{\mathrm{eq}}-\Delta \phi_{\mathrm{ML}}{ }^{0 \prime}\right) / R T\right\}=I_{\mathrm{org}} /\left[\mathrm{M}^{+}\right] .
$$

Then, assuming $1 \gg\left(K_{\mathrm{ML}}[\mathrm{L}]_{\mathrm{org}} / K_{\mathrm{D}, \mathrm{L}}\right) \exp \left\{F\left(\Delta \phi_{\mathrm{M}}{ }^{\prime \prime}-\Delta \phi_{\mathrm{ML}}{ }^{0}\right) / R T\right\} \quad\left[=\left(K_{\mathrm{ML}}[\mathrm{L}]_{\mathrm{org}} / K_{\mathrm{D}, \mathrm{L}}\right) \times \exp \left\{F\left(\Delta \phi_{\mathrm{eq}}-\right.\right.\right.$ $\left.\left.\left.\Delta \phi_{\mathrm{ML}}{ }^{\prime \prime}\right) / R T\right\} / \exp \left\{F\left(\Delta \phi_{\mathrm{eq}}-\Delta \phi_{\mathrm{M}}{ }^{\prime \prime}\right) / R T\right\}\right]$, we easily obtain

$$
\Delta \phi_{\mathrm{M}}{ }^{\prime \prime} \approx \Delta \phi_{\mathrm{eq}}-0.05916 \times \log \left(I_{\mathrm{org}} /\left[\mathrm{M}^{+}\right]\right) .
$$

Introducing the determined $\Delta \phi_{\mathrm{eq}}, I_{\mathrm{org}}$ and $\left[\mathrm{M}^{+}\right]$values in this equation, we can immediately calculate $\Delta \phi_{\mathrm{M}}{ }^{0 \prime}$. In the $K_{\mathrm{ML}}[\mathrm{L}]_{\text {org }} / K_{\mathrm{D}, \mathrm{L}}$ terms, the maximum $K_{\mathrm{NaL}} / K_{\mathrm{D}, \mathrm{L}}$ value in Eq. (7) was $10^{1.73}(=54) \mathrm{mol}^{-1} \mathrm{dm}^{3}$ for the $18 \mathrm{C} 6$ extraction into $\mathrm{NB}$, while the minimum value was $10^{-1.97}(=0.011)$ for the $\mathrm{B} 15 \mathrm{C} 5$ extraction into DCM. Therefore, the above assumption can hold on Eq. (7), because the $[\mathrm{L}]_{\mathrm{org}}\left(K_{\mathrm{NaL}} / K_{\mathrm{D}, \mathrm{L}}\right)$ terms become much smaller than unity in the experimental $[\mathrm{L}]_{\text {org }}$ ranges (for example, see the $[\mathrm{L}]_{\text {org }}$ ranges in Fig. 1).

Thus, the standard formal potentials for the $\mathrm{Na}^{+}$transfers were calculated at the number of data $=4$. Their $\Delta \phi_{\mathrm{Na}}{ }^{0 \prime}$ values at $298 \mathrm{~K}$ were $0.33_{9} \pm 0.07_{6} \mathrm{~V}$ for the DCM extraction-systems, $0.26_{1} \pm 0.09_{9}$ for DCE and $0.20_{6} \pm 0.07_{7}$ for NB. The value at the transfer across the water/NB interface became $0.24_{5} \pm 0.04_{3} \mathrm{~V}$, neglecting the $\Delta \phi_{\mathrm{Na}}{ }^{\prime \prime}$ data for the B15C5 extraction, where its $I_{\mathrm{NB}}$ value was largely different from those of the other L extraction into NB (see Table 1). These results indicate that $\mathrm{Na}^{+}$is easy to transfer from the water phase into the org phase in the order of org $=\mathrm{DCM} \leq \mathrm{DCE} \leq$ NB. The value averaged for the DCE extraction systems agreed with the values $(0.30 \& 0.36 \mathrm{~V})$ (Kudo et al., 2011; Kudo \& Takeuchi, 2013), which have been reported at the $\mathrm{Na}^{+}$transfer across the water/DCE interface by one (Y. K.) of the authors, within experimental errors. Also, the maximum value $(=0.28-0.29 \mathrm{~V})$ obtained from the deviation for the NB systems was somewhat smaller than $\Delta \phi_{\mathrm{Na}^{0 \prime}}{ }^{0 \prime} 0.31 \mathrm{~V}$ reported before (Kudo et al., 2011). These facts suggest that the above method is intrinsically effective for the determination of the $\Delta \phi_{\mathrm{M}}{ }^{0 \prime}$ values and at the same time the value for the DCM system is valid. For the DCM systems, the $\log K_{\mathrm{D}, \mathrm{Na}}$ values at $\Delta \phi_{\mathrm{eq}} \neq 0 \mathrm{~V}$ in Table 1 were estimated from the $\Delta \phi_{\mathrm{Na}}{ }^{0 \prime}$ value $(=0.34 \mathrm{~V})$ described above.

\section{Conclusion}

For the DCM and DCE extraction systems with similar polarities, the $\log K_{\mathrm{ex} \pm}$ values were proportional to the $-\Delta \phi_{\mathrm{eq}}$ ones. The $K_{\text {ext }}$ values estimated previously for the NB system were 18-times larger in maximum than those experimentally-determined here. The differences between the $\Delta \phi_{\mathrm{eq}}$ and $\Delta \phi_{\mathrm{eq}, \mathrm{cb}}$ values were found out in several cases, but they were less than $0.04 \mathrm{~V}$. However, this study strongly ensures the dep determination with the $K_{\mathrm{D}, \mathrm{A}}$ value obtained from the extraction experiment. Also, the procedure based on Eq. (8) can be used for the $\Delta \phi_{\mathrm{M}}{ }^{\prime \prime}$ determination, although improvements of the precision of the $\Delta \phi_{\mathrm{M}}{ }^{0 \prime}$ values, actually the $\Delta \phi_{\mathrm{eq}}$ ones, will be required for its procedure. For the DCM and DCE systems, the benzo-group substitution on L caused an increase in $K_{1, \text { org }}$, while for the NB system the increase in the ring-size of $\mathrm{L}$ did that in $K_{1, \mathrm{NB}}$. Also, the increase in the ring size or the donor oxygen-atoms caused that in $K_{\mathrm{NaL}, \text { org }}$ for all the diluent systems employed. Lastly, the authors were convinced that the presence of dep was confirmed also in the NaPic extraction systems with some $\mathrm{L}$.

\section{Acknowledgments}

The authors thank Dr. Yasuyuki Takeda, an emeritus professor of Chiba University, for his permission. He readily agreed to their request that they would like to reuse the previously-reported extraction data for the DCM and DCE systems. Also, the authors thank Dr Hideaki Shirota, who belongs to Chiba University, for his valuable support in preparing the introduction of this paper.

\section{References}

Danesi, P. R., Meider-Gorican, H., Chiarizia, R., \& Scibona, G. (1975). Extraction selectivity of organic solutions of a cyclic polyether with respect to the alkali cations. Journal of Inorganic and Nuclear Chemistry, 37, 1479-1483. https://doi.org/10.1016/0022-1902(75)80794-9 
Danil de Namor, A. F., Traboulssi, R., Salazar, F. F., Dianderas de Acosta, V., .. Portugal, J. M. (1989). Transfer and partition free energies of $1: 1$ electrolytes in the water-dichloromethane solvent system at $298.15 \mathrm{~K}$. Journal of Chemical Society Faraday Transactions 1(85), 2705-2712. https://doi.org/10.1039/f19898502705

Iwachido, T., Minami, M., Naito, H., \& Tôei, K. (1982). The Extractability of Potassium as Picrates (KPic and K(L)Pic, L: 18-Crown-6) and Its Relationship to the Properties of the Solvents. Bulletin of the Chemical Society of Japan, 55, 2378-2382. https://doi.org/10.1246/bcsj.55.2378

Iwachido, T., Minami, M., Sadakane, A., \& Tôei, K. (1977). The Coextraction of Water into Nitrobenzene with Alkaline Earth Metal 2,2',4,4',6,6'-Hexanitro-Diphenyl- Aminates in the Presence of Crown Ethers. Chemistry Letters, 6, 1511-1514. https://doi.org/10.1246/cl.1977.1511

Katsuta, S., \& Takeda, Y. (2003). Transfer activity coefficients of crown ethers and their alkali metal ion complexes between water and polar nonaqueous solvents. Bunseki Kagaku (Analytical Chemistry), 52, 89-105 (in Japanese). https://doi.org/10.2116/bunsekikagaku.52.89

Kikuchi, Y., \& Sakamoto, Y. (2000). Complex formation of alkali metal ions with 18-crown-6 and its derivatives in 1,2-dichloroethane. Analytica Chimica Acta, 403, 325-332. https://doi.org/10.1016/S0003-2670(99)00648-0

Kikuchi, Y., Arayashiki, Y., \& Aneda, T. (2001). Hydration to Benzo-15-crown-5, Benzo-18-crown-6 and the Benzo-18-crown-6-Potassium Ion Complex in the Low-Polar Organic Solvents. Analytical Sciences, 17, 421-424. https://doi.org/10.2116/analsci.17.421

Kolthoff, I. M. (1981). Ionic strength effect on extraction of potassium complexed with crown ether 18-crown-6. Preliminary communication. Canadian Journal of Chemistry, 59, 1548-1551. https://doi.org/10.1139/v81-227

Kudo, Y. (2015). On the Expression of Extraction Constants without Equilibrium Interfacial Potential Differences. Review of Polarography, 61, 87-92 (in Japanese). https://doi.org/10.5189/revpolarography.61.87

Kudo, Y. (2016). On Two Kinds of Equilibrium Constants in an Extraction System: Does an Interfacial Equilibrium Potential Control the Equilibrium Constant? Journal of Analytical \& Pharmaceutical Research, 3, 00078. https://doi.org/10.15406/japlr.2016.03.00078

Kudo, Y., \& Katsuta, S. (2015). On an expression of Extraction Constants without Interfacial Equilibrium-Potential Differences for the Extraction of Univalent and Divalent Metal Picrates by Crown Ethers into 1,2-Dichloroethane and Nitrobenzene. American Journal of Analytical Chemistry, 6, 350-363. https://doi.org/10.4236/ajac.2015.64034

Kudo, Y., \& Takeuchi, T. (2013). Determination of Individual Distribution Constants of Alkali Metal Ions into 1,2-Dichloroethane: A Consideration for Difference between their Constants and Tose Determined by Ion-Transfer Voltammetry. Chemistry Journal, 3, 37-43. Available online at ISSN 2049-954X

Kudo, Y., \& Takeuchi, T. (2014). On the Interfacial Potential Deferences for the Extraction of Alkaline-Earth Metal Picrates by 18-Crown-6 Ether Derivatives into Nitrobenzene. Journal of Thermodynamics \& Catalysis, 5. https//:dx.doi.org/10.4172/2157-7544.1000133

Kudo, Y., Harashima, K., Hiyoshi, K., Takagi, J., Katsuta, S., \& Takeda, Y. (2011). Extraction of Some Univalent Salts into 1,2-Dichloroethane and Nitrobenzene: Analysis of Overall Extraction Equilibrium Based on Elucidating Ion-pair Formation and Evaluation of Standard Potentials for Ion Transfers at the Interfaces between Their Diluents and Water. Analytical Sciences, 27, 913-919. https://doi.org/10.2116/analsci.27.913

Kudo, Y., Harashima, K., Katsuta, S., \& Takeda, Y. (2011a). Solvent Extraction of Sodium Permanganate by Mono-benzo 3m-Crown- $m$ Ethers $(m=5,6)$ into 1,2-Dichloroethane and Nitrobenzene: a Method which Analyzes the Extraction System with the Polar Diluents. International Journal of Chemistry, 3, 99-107. https://doi.org/10.5539/ijc.v3n1p99

Kudo, Y., Kaminagayoshi, A., Ikeda, S., Yamada, H., \& Katsuta, S. (2016). Brief Determination of Standard Formal Potentials for the Transfers of Several Pairing Anions across the Nitorobenzene/Water Interface by $\mathrm{Na}(\mathrm{I})$ Extraction with 18-Crown-6 Ether. Journal of Analytical \& Bioanalytical Technequies, 7. https//dx.doi.org/10.4172/2155-9872.1000319

Kudo, Y., Katsuta, S., \& Takeda, Y. (2012). Evaluation of overall extraction constants for the crown ether-complex ions of alkali and alkaline-earth metal with counter picrate ions from water into nitrobenzene based on their component equilibrium constants. Journal of Molecular Liquids, 173, 66-70. https://doi.org/10.1016/j.molliq.2012.06.003

Kudo, Y., Katsuta, S., Ohsawa, Y., \& Nozaki, K. (2015). Solvent Extraction of Cadimium Picrate by 18-Crown-6 Ether into Several Less-polar Diluents and Nitrobenzene: Re-evaluation of the Corresponding Overall Extraction Systems. Journal of Thermodynamics \& Catalysis, 6. https://doi.org/10.4172/2157-7544.1000146 
Kudo, Y., Nakamori, T., \& Numako, C. (2016a). Extraction of Sodium Picrate by $3 m$-Crowm- $m$ Ethers and Their Monobenzo Derivatives $(m=5,6)$ into Benzene: Estimation of Their Equilibrium-Potential Differences at Less-Polar Diluent/Water Interface by an Extraction Method. Journal of Chemistry, 2016.

https://doi.org/10.1155/2016/5175746

Kudo, Y., Ogihara, M., Katsuta, S., \& Takeda, Y. (2014). An Electrochemical Understanding of Extraction of Silver Picrate by Benzo-3m-Crown- $m$ Ethers $(m=5,6)$ into 1,2-Dichloroethane and Nitrobenzene. American Journal of Analytical Chemistry, 5, 433-444. https://doi.org/10.4236/ajac.2014.57052

Kudo, Y., Takahashi, Y., Numako, C., \& Katsuta, S. (2014a). Extraction of lead picrate by 18-crown-6 ether into various diluents: Examples of sub-analysis of overall extraction equilibrium based on component equilibria. Journal of Molecular Liquids, 194, 121-129. https://doi.org/10.1016/j.molliq.2014.01.017

Kudo, Y., Zhao, Y., Harashima, K., \& Takeda, Y. (2013). Analysis of Extraction Equilibria of $\mathrm{NaMnO}_{4}$ into 1,2-Dichloroethane and Nitrobenzene by Crown Ethers of Which Complexing-abilities are Inhibited by their Dimer Formation. Chemistry Journal, 3, 30-36. Available online at ISSN 2049-954X

Levitskaia, T. G., Maya, L., Van Berkel, G. J., \& Moyer, B. A. (2007). Anion Partitioning and Ion-Pairing Behavior of Anions in the Extraction of Cesium Salts by 4,5"-Bis(tert-octylbenzo)dibenzo-24-crown-8 in 1,2-Dichloroethane. Inorganic Chemistry, 46, 261-272. https://doi.org/10.1021/ic061605k

Lide, D. R. (1995). Hand Book of Organic Solvents, CRC Press, Boca Raton, USA.

Makrlík, E., \& Vaňura, P. (1999). Stability of complex of $\mathrm{Na}^{+}$with 18 -crown-6 in nitrobenzene saturated with water. Journal of Radioanalytical and Nuclear Chemistry, 240, 339-341. https://doi.org/10.1007/BF02349175

Markin, V. S., \& Volkov, A. G. (1989). The Gibbs Free Energy of Ion Transfer between Two Immiscible Liquids. Electrochimica Acta, 34, 93-107. https://doi.org/10.1016/0013-4686(89)87072-0

Osakai, T., \& Ebina, K. (1998). Non-Bornian Theory of the Gibbs Energy of Ion Transfer between Two Immiscible Liquids. Journal of Physical Chemistry B, 102, 5691-5698. https://doi.org/10.1021/jp9814193

Takeda, Y. (2002). Extraction of alkali metal picrates with 18-crown-6, benzo-18-crown-6, and dibenzo-18-crown-6 into various organic solvents. Elucidation of fundamental equilibria governing the extraction-ability and-selectivity. Bunseki Kagaku (Analytical Chemistry), 51, 515-525 (in Japanese). https//doi.org/10.2116/bunsekikagaku.51.515

Takeda, Y., \& Takagi, T. (1994). Solvent Effects on Extraction of Sodium Picrate with 15-Crown-5. The Determination of Ion-Pair Formation Constant of Crown Ether-Metal Salt 1:1:1 Complex in Water. Bulletin of the Chemical Society of Japan, 67, 56-60. https://doi.org/10.1246/bcsj.67.56

Takeda, Y., Ezaki, T.; Kudo, Y., \& Matsuda, H. (1995a). Distribution Study on Electroneutral and Protonated Amino Acids between Water and Nitrobenzene. Determination of the Standard Ion-Transfer Potentials of Protonated Amino Acids. Bulletin of the Chemical Society of Japan, 68, 787-790. https://doi.org/10.1246/bcsj.68.787

Takeda, Y., Hashimoto, K., Yoshiyama, D., \& Katsuta, S. (2002). Extraction of Alkali Metal (Li, Na, K) Picrates with Benzo-15-crown-5 into Various Organic Solvents. Elucidation of Fundamental Equilibria Determining the Extraction-ability and -selectivity. Journal of Inclusion Phenomena and Macrocyclic Chemistry, 42, 323-331. https://doi.org/10.1023/A:1016042402828

Takeda, Y., Kawarabayashi, A., Endō, K., Yahata, T., Kudo, Y., \& Katsuta, S. (1998). Solvent Extraction of Alkali Metal (Li-Cs) Picrates with18-Crown-6 into Various Diluents. Elucidation of Fundamental Equilibriawhich Govern the Extraction-Ability and -Selectivity. Analytical Sciences, 14, 215-223. https://doi.org/10.2116/analsci.14.215

Takeda, Y., Kawarabayashi, A., Takahashi, K., \& Kudo, Y. (1995). Extraction of Alkali Metal Picrates with Benzo-18-crown-6 into Various Organic Solvents. Fundamental Equilibria which Govern the Highest Extraction Selectivity for $\mathrm{K}^{+}$among Alkali Metal Ions. Bulletin of the Chemical Society of Japan, 68, 1309-1314. https://doi.org/10.1246/bcsj.68.1309

Takeda, Y., Wada, Y., \& Fujiwara, S. (1981). The Solvent Extraction of Alkali Metal Picrates by Benzo-15-crown-5. Bulletin of the Chemical Society of Japan, 54, 3727-3730. https://doi.org/10.1246/bcsj.54.3727 


\section{Appendix A}

The $\left[\mathrm{Na}^{+}\right],[\mathrm{L}]_{\mathrm{NB}}$ and $\left[\mathrm{Pic}^{-}\right]$terms were expressed as the following equations:

$$
\begin{gathered}
{\left[\mathrm{Na}^{+}\right]=\left([\mathrm{Na}]_{\mathrm{t}}-A b\right) /\left\{1+K_{\mathrm{NaPic}}\left[\mathrm{Pic}^{-}\right]+K_{\mathrm{NaL}} K_{\mathrm{D}, \mathrm{L}}^{-1}\left(1+K_{1}\left[\mathrm{Pic}^{-}\right]\right)[\mathrm{L}]_{\mathrm{NB}}\right\},} \\
{[\mathrm{L}]_{\mathrm{NB}}=\left([\mathrm{L}]_{\mathrm{t}}-A b\right) /\left[1+K_{\mathrm{D}, \mathrm{L}}^{-1}\left\{1+K_{\mathrm{NaL}}\left(1+K_{1}\left[\mathrm{Pic}^{-}\right]\right)\left[\mathrm{Na}^{+}\right]\right\}\right]}
\end{gathered}
$$

and

$$
\left[\mathrm{Pic}^{-}\right] \approx\left([\mathrm{Pic}]_{\mathrm{t}}-A b\right) /\left\{1+\left(K_{\mathrm{NaPic}}+K_{\mathrm{NaL}} K_{1} K_{\mathrm{D}, \mathrm{L}}{ }^{-1}[\mathrm{~L}]_{\mathrm{NB}}\right)\left[\mathrm{Na}^{+}\right]+\left(K_{\mathrm{HPic}}+K_{\mathrm{ex}, \mathrm{HPic}}\right)\left[\mathrm{H}^{+}\right]\right\} .
$$

Here, $[j]_{\mathrm{t}}, K_{\mathrm{NaPic}}, K_{\mathrm{HPic}}\left(=1 / K_{\mathrm{a}}\right)$ and $K_{\mathrm{ex}, \mathrm{HPic}}$ refer to a total concentration of species $j\{=\mathrm{Na}(\mathrm{I}), \mathrm{L} \& \mathrm{Pic}(-\mathrm{I})\}$, an ion-pair formation constant for $\mathrm{Na}^{+} \mathrm{Pic}^{-}$in water, an association constant for HPic in water and an extraction constant of HPic into the NB phase, respectively. These equilibrium constants are available from references and the numerators in Eqs. (A1)-(A3) are obtained from the experiments. Also, the symbol, $A b$, shows the total concentration of the species with $\mathrm{Na}$ (I) in the NB phase and can be determined by the AAS measurements, where $A b$ nearly equals to the total $\mathrm{Na}(\mathrm{I})$ concentration in the NB phase determined by the AAS measurements $\}$ - \{the blank value $\}$ (see the section 2.3).

\section{Appendix B}

Referring to previous papers (Takeda \& Takagi, 1994; Takeda et al., 1995; Takeda et al., 1998; Takeda et al., 2002; Kudo et al., 2013; Takeda et al., 1981), the authors classified the determination of compositions of species extracted into the org phase into the four types. As can be seen from Table B1, the types were of $J, \Gamma$, ${ }^{\mathrm{S}} I$, and $U$. In the type $J$, the extraction of MLA accompanies that of $\mathrm{ML}^{+}$with the counter anion $\mathrm{A}^{-}$in the lower [L] org range (Kudo et al., 2011a). In the type $\Gamma$, the extraction of MLA accompanies the L's dimerization in the higher [L] org range (Kudo et al., 2013). Also, the type ${ }^{\mathrm{S}} I$ shows that the ion-pair complex MLA is a major species which is extracted into the org phase (Takeda \& Takagi, 1994; Takeda et al., 1995; Takeda et al., 1998; Takeda et al., 2002): this is a standard type. The type $U$ yields the extraction of a sandwich-type complexes $\mathrm{ML}_{2} \mathrm{~A}$ in the higher $[\mathrm{L}]_{\mathrm{org}}$ range (Takeda et al., 1981). The extraction processes in this study corresponded to the types ${ }^{\mathrm{S}} I$ and $J$ (see the section 3.1).

\begin{tabular}{|c|c|c|c|c|c|}
\hline Plot & Slope $(a)$ & Plot shape \& type & Plot & $\begin{array}{l}\text { Slope } \\
\left(a^{\prime}\right)\end{array}$ & $\begin{array}{l}\text { Composition etc. of major species } \\
\text { extracted }\end{array}$ \\
\hline \multirow[t]{4}{*}{$\begin{array}{l}\log \left(D /\left[\mathrm{A}^{-}\right]\right) \\
v s \cdot \log [\mathrm{L}]_{\mathrm{org}}\end{array}$} & $\begin{array}{l}a<1 \text { in the } \\
\text { lower }[\mathrm{L}]_{\text {org }} \\
\text { range }^{b}\end{array}$ & $J$-shaped curve: type $J$ & $\begin{array}{l}2 \log D v s . \\
\log [\mathrm{L}]_{\mathrm{org}}\end{array}$ & $a^{\prime} \approx 1$ & $\begin{array}{l}\text { Dissociable complexes } \mathrm{ML}^{+} \text {with } \\
\mathrm{A}^{-} \text {at } \mathrm{M}: \mathrm{L}(\mathrm{A})=1: 1(: 1)\end{array}$ \\
\hline & $\begin{array}{l}a<1 \text { in the } \\
\text { higher }^{\text {range }}{ }^{d} \quad[\mathrm{~L}]_{\text {org }}\end{array}$ & $\Gamma$-shaped curve: type $\Gamma$ & $\rightarrow$ & $\rightarrow$ & $\begin{array}{l}\text { L's dimerization in the org phase \& } \\
\text { ion-pair complexes at } \mathrm{M}: \mathrm{L}(\mathrm{A})= \\
1: 1(: 1)\end{array}$ \\
\hline & $a \approx 1^{a}$ & $\begin{array}{l}\text { Monotonically } \\
\text { increased shape: type } \\
\mathrm{s}_{I}\end{array}$ & $\rightarrow$ & $\rightarrow$ & $\begin{array}{l}\text { Ion-pair complexes at } \mathrm{M}: \mathrm{L}(: \mathrm{A})= \\
1: 1(: 1)\end{array}$ \\
\hline & $a>1^{e}$ & $\begin{array}{l}\text { Hemi-parabolic curve: } \\
\text { type } U\end{array}$ & $\rightarrow$ & $\rightarrow$ & $\begin{array}{l}\text { Sandwich-type } \quad \text { complexes } \\
\text { M:L(:A) = 1:2(:1) etc. }\end{array}$ \\
\hline
\end{tabular}

Table B1. Classification of plots for the determination of composition of major species extracted into the org phase in the $\mathrm{M}^{+} \mathrm{A}^{-}$extraction with $\mathrm{L}$

${ }^{a}$ The plot was based on $\log \left(D /\left[\mathrm{A}^{-}\right]\right) \approx \log [\mathrm{L}]_{\text {org }}+\log K_{\text {ex. }}$ See Refs. Takeda \& Takagi, 1994; Takeda et al., 1995; Takeda et al., 1998; Takeda et al., 2002. ${ }^{b}$ Ref. Kudo et al., 2011a. ${ }^{c}$ Based on $2 \log D \approx \log [\mathrm{L}]_{\text {org }}+\log K_{\text {ext. }}{ }^{d}$ It was based on $\log \left(D /\left[\mathrm{A}^{-}\right]\right) \approx \log \left\{[\mathrm{L}]_{\text {org }} /\left(1+2 K_{\text {dim }}[\mathrm{L}]_{\text {org }}\right)\right\}+\log K_{\text {ex }}$ where $K_{\text {dim }}=\left[\mathrm{L}_{2}\right]_{\text {org }} /[\mathrm{L}]_{\text {org }}{ }^{2}$. See Ref. Kudo et al., 2013. ${ }^{e}$ It was based on essentially $\log \left(D /\left[\mathrm{A}^{-}\right]\right) \approx m \log [\mathrm{L}]_{\text {org }}+\log K_{\text {ex }}{ }^{\prime}$ where $K_{\text {ex }}{ }^{\prime}=\left[\mathrm{ML}_{m} \mathrm{~A}\right]_{\text {org }} /\left(\left[\mathrm{M}^{+}\right][\mathrm{L}]_{\text {org }}{ }^{m}\left[\mathrm{~A}^{-}\right]\right)$at $m=2$. See Ref. Takeda et al., 1981.

\section{Appendix C}

One (Y. K.) of the authors has proposed empirical parameters for predicting order in magnitudes of the $K_{1, \text { org }}$ or $K_{\text {NaL,org }}$ values among Ls at org = benzene (Kudo et al., 2016a). Revised parameters were used here for the prediction. Table $\mathrm{C} 1$ is a revised table, in which the figures of the parameter $B$ were partially revised from 1 to 0.8 . The combined parameters in the text show how the properties based on their parameters contribute the order of the equilibrium constants among Ls, but they do not necessarily explain a reason for the order. Also, the parameters seem to be ineffective for systems with the strong solute-solvent interaction, such as the solute-water molecules interaction. 
Table C1. A measure of basic parameters ${ }^{\mathrm{a}}$ for comparison between Ls

\begin{tabular}{lllllll}
\hline L & Parameter $B$ & $C$ & $M^{\prime}$ & $N$ & $S$ & $V$ \\
\hline 15C5 & 2 & 1 & 2 & 5 & 2 & 0 \\
B15C5 & $0.8^{b}$ & 1 & 2 & 5 & 1 & 2 \\
\hline $18 \mathrm{C} 6$ & 2 & 2 & 0 & 6 & 2 & 1 \\
B18C6 & $0.8^{b}$ & 2 & 0 & 6 & 1 & 3 \\
DB18C6 & 0 & 2 & 0 & 6 & 0 & 4 \\
\hline
\end{tabular}

${ }^{a}$ The parameters are of empirical values and express the following characteristics of L. $B$ : basicity of donor O atoms; $C$ : cavity size; $M^{\prime}: \mathrm{Na}^{+}$selectivity; $N$ : number of donor O atoms; $S$ : softness of ring skeleton; $V$ : molar volume. See Ref. Kudo et al., 2016a. ${ }^{b}$ Figures revised in this study.

\section{Copyrights}

Copyright for this article is retained by the author(s), with first publication rights granted to the journal.

This is an open-access article distributed under the terms and conditions of the Creative Commons Attribution license (http://creativecommons.org/licenses/by/4.0/). 